Article

\title{
Formation of Prenylated Chalcone Xanthohumol Cocrystals: Single Crystal X-ray Diffraction, Vibrational Spectroscopic Study Coupled with Multivariate Analysis
}

\author{
Iwona Budziak ${ }^{1}\left(\mathbb{D}\right.$, Marta Arczewska ${ }^{2, *,+}$ and Daniel M. Kamiński ${ }^{3, *,+}+(\mathbb{C}$ \\ 1 Department of Chemistry, University of Life Sciences in Lublin, Akademicka 15, 20-950 Lublin, Poland; \\ iwona.budziak@up.lublin.pl \\ 2 Department of Biophysics, University of Life Sciences in Lublin, Akademicka 13, 20-950 Lublin, Poland \\ 3 Department of General and Coordination Chemistry and Crystallography, Institute of Chemical Sciences, \\ Maria Curie-Sklodowska University in Lublin, pl. Marii Curie-Skłodowskiej 2, 20-031 Lublin, Poland \\ * Correspondence: marta.arczewska@up.lublin.pl (M.A.); daniel.kaminski@umcs.pl (D.M.K.); \\ Tel./Fax: +(48-81)445-69-05 (M.A.); Tel./Fax: +(48-81)537-56-44 (D.M.K.) \\ + The authors contributed equally to this paper.
}

Received: 23 October 2019; Accepted: 19 November 2019; Published: 21 November 2019

check for updates

\begin{abstract}
Four novel xanthohumol $(\mathrm{XN})$ cocrystals with pharmaceutically acceptable coformers, such as nicotinamide (NIC), glutarimide (GA), acetamide (AC), and caffeine (CF) in the 1:1 stoichiometry were obtained by the slow evaporation solution growth technique. The structure of the cocrystals was determined by single crystal X-ray diffraction. The analysis of packing and interactions in the crystal lattice revealed that molecules in the target cocrystals were packed into almost flat layers, formed by the $\mathrm{O}-\mathrm{H} \cdots \mathrm{O}, \mathrm{O}-\mathrm{H} \cdots \mathrm{N}$, and $\mathrm{N}-\mathrm{H} \cdots \mathrm{O}$-type contacts between the xanthohumol and coformer molecules. The results provided details about synthons responsible for crystal net stabilization and all hydrogen bonds observed in the crystal lattice. The main synthon was formed via the hydrogen bond between the hydroxyl group in the $\mathrm{B}$ ring of $\mathrm{XN}$ and coformers. The three-dimensional crystal lattice was stabilized by the hydrogen $\mathrm{XN}-\mathrm{XN}$ interactions whereas the $\pi-\pi$ stacking interactions played an additional role in layer binding, with the exception of low quality cocrystals formed with caffeine. Application of FTIR and Raman spectroscopy confirmed that the crystalline phase of obtained cocrystals was not a simple combination of individual components and completely different crystal phases resulted from the effect of intermolecular interactions. The multivariate analysis showed the changes in the spectra, and this technique can be applied in a combination with vibrational spectroscopy for fast screening of new crystal phases. Additionally, the solubility studies of pure $\mathrm{XN}$ and its cocrystals exhibited a 2.6-fold enhancement in $\mathrm{XN}$ solubility in aqueous solution for $\mathrm{XN}-\mathrm{AC}$ and, to a lesser extent, for other cocrystals.
\end{abstract}

Keywords: prenylated chalcones; xanthohumol; crystal engineering; XRD, FTIR; Raman spectroscopy; principal component analysis (PCA)

\section{Introduction}

Xanthohumol (2',4',4-trihydroxy-6'-methoxy-3'-prenylchalcone, $\mathrm{XN}$, Figure 1) is a prenylated chalcone that occurs mainly in hops plant (Humulus lupulus L.), being the principal prenyloflavonoid of the female inflorescences [1,2]. Although the molecular structure of $\mathrm{XN}$ was identified in the 1950s [3,4], a growing interest in this molecule was observed only recently due to its numerous health-promoting properties $[5,6]$. XN has displayed a broad bioactivity spectrum, among other 
anticancer and chemoprotection [5,7], antioxidative [7,8], anti-inflammatory $[9,10]$, and antiangiogenic activities [11,12] and even inhibition of osteoporosis in post-menopausal women activities [13] has been reported.

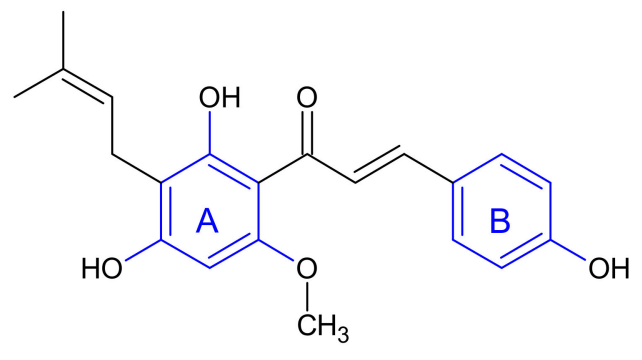

(a)

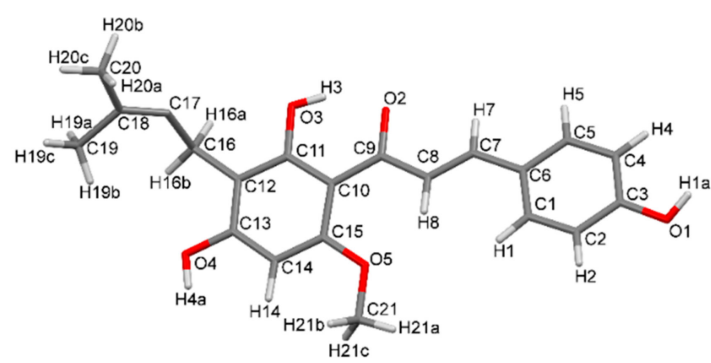

(b)

Figure 1. (a) Scheme of xanthohumol $(\mathrm{XN})$ structure; (b) atom numbering in the $\mathrm{XN}$ cocrystals. For more than one $\mathrm{XN}$ molecule in the asymmetric part of a unit cell, the suffixes A, B, C, and D were added, see crystallographic information files (CIFs) in the Supplementary Materials.

Structurally, XN belongs to the open-chain flavonoids and is composed of two aromatic rings (A- and B-rings) connected by $\alpha, \beta$-unsaturated ketone moiety and carrying a 3'-isoprenyl unit (3,3-dimethylallyl) [14] (Figure 1a). The presence of a prenyl moiety and hydroxyl groups in the XN structure determines largely its pharmacological activities [15-17]. The mechanism of covalent binding of $\mathrm{XN}$ with cytosolic proteins via electrophilic sites (e.g., the $\alpha, \beta$-unsaturated carbonyl group) also strongly influences the distribution of $\mathrm{XN}$ and could be responsible for its unique health-oriented effects [18].

Unfortunately, the bioavailability of orally administrated xanthohumol is considered to be extremely low as a result of rapid excretion, or extensive metabolism [19]. Therefore, dietary consumption seems to be insufficient to obtain health related benefits. According to the biopharmaceutics classification system (BCS) the solubility and permeability properties are the major factors used to describe oral absorption of poorly water-soluble active compounds [20]. In this context, improvement of the $\mathrm{XN}$ bioavailability as well as its pharmacokinetic profile can depend to a great extent on the modification of physicochemical properties by creating binary-component systems in the form of cocrystals. As a new approach in the pharmaceutical industry, cocrystallization appears to be a promising way to modify water solubility, dissolution rate, and other physicochemical properties of biologically active compounds which contributes to their therapeutic effects [21-24]. Contrary to the forms of amorphous pharmaceutical substances, cocrystals have better defined physicochemical parameters and are thermodynamically more stable which is important during production and storage [25]. Cocrystals are single phase materials composed of two or more different molecular and/or ionic compounds generally in a stoichiometric ratio, bound by noncovalent interactions, predominantly hydrogen bonds, which are neither solvates nor simple salts [26]. As compared to the neat active pharmaceutical ingredient (API), cocrystals frequently display unique properties, which can be tailored through the changes of the coformer or packing of the molecules in the crystal lattice (cocrystal polymorphism) [27].

Polyphenols and flavonoids with the availability of plenty of hydrogen bond donors/acceptors are suggested to be worth of study from a crystal engineering perspective. Although in recent years the amount of studies on the cocrystallization of flavonoids in the aspect of their bioavailability has increased, there are few scientific reports on cocrystals formation by naturally occurring chalcones. In one of them, the enhanced dissolution rates for isoliquiritigenin (ISL) with the nicotinamide and isonicotinamide cocrystals were demonstrated, consequently aiming at improvement of ISL in vivo bioavailability [28]. 
The research of cocrystal structure and applications showed an exponential increase in the past decade, evident in the number of cocrystal structures deposited in the Cambridge Structural Database (CSD) and cocrystal related patent applications. Moreover, the polyphenols are more likely to form supramolecular synthons with such functional groups as carbonyl and aromatic nitrogen. In cocrystallization between the flavonoids and the compounds with organic nitrogen, the $\mathrm{O}-\mathrm{H} \cdots \mathrm{N}$ heterosynthon has been reported to be the most competitive synthon [29-32].

Various techniques of cocrystal preparation have been reported such as solvent evaporation, solid state grinding, solution crystallization, slurry conversion, melt crystallization, hot melt extrusion, and spray crystallization [24]. The most commonly used technique for preparing cocrystals is the solvent evaporation method - therefore in this paper the cocrystallization of XN via the mentioned approach was exploited [33].

In light of the above-mentioned facts, the cocrystallization of xanthohumol with the commonly used coformers, nicotinamide (NIC), glutarimide (GA), acetamide (AC), and caffeine (CF) is reported herein (Scheme 1). The main concept behind this paper is to determine the structure of target cocrystals and indicate similarities and differences using various techniques such as single crystal X-ray diffraction, Fourier transform infrared (FTIR), and Raman spectroscopy as well as two multivariate analysis methods (i.e., principal component analysis (PCA) and cluster analysis (CA)). According to the current knowledge, the subject matter is innovative since so far cocrystallization has not been used to improve xanthohumol solubility. FTIR and Raman spectroscopy coupled with the multivariate statistical approach are effective methods to confirm new forms of cocrystals. It is worth noting that up to now there has existed only one crystallographic structure of XN present in the Cambridge Crystallographic Data Centre (CCDC) base [34].

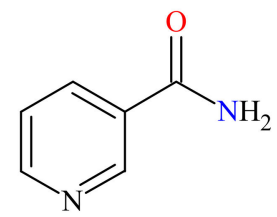

Nicotinamide (NIC)<smiles>CC(N)=O</smiles>

Acetamide (AC)<smiles>O=C1CCCC(=O)N1</smiles>

Glutarimide (GA)<smiles>Cn1c(=O)c2c(ncn2C)n(C)c1=O</smiles>

Caffeine (CF)

Scheme 1. Chemical structure of coformers employed in this study.

\section{Results and Discussion}

The morphology of the selected cocrystals revealed that they are fragile and have defined facets. All of them have a layered structure and can be easily cleaved perpendicular to the $c$ crystallographic direction (Figure 2a-e). Moreover, the XN-CF cocrystals have many defects that affect the quality of their structure (Figure 2e). Crystallographic parameters of the target crystals are listed in Table 1.

a)

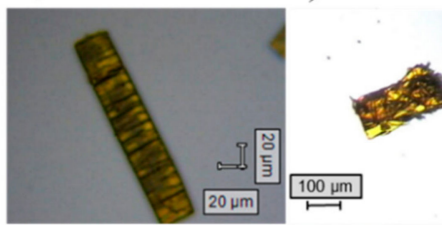

c)

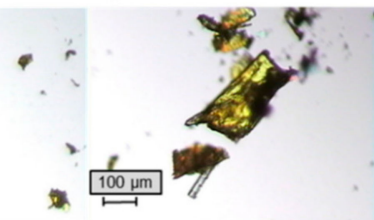

d)

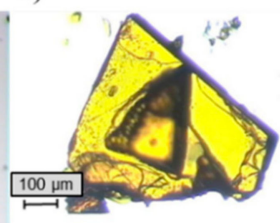

e)

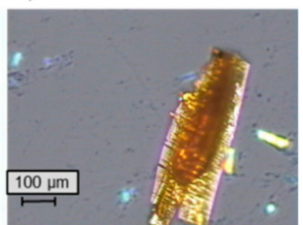

Figure 2. Micrographs of cocrystals obtained with a Nikon Eclipse 50iPOL microscope with the charge-coupled device (CCD) camera. (a) XN, (b) XN-NIC, (c) XN-GA, (d) XN-AC, and (e) XN-CF. 
Table 1. Crystallographic parameters and refinement details for the target cocrystals.

\begin{tabular}{|c|c|c|c|c|}
\hline & XN-NIC (1:1) & XN-GA (1:1) & $\mathrm{XN}-\mathrm{AC}(1: 1)$ & $\mathrm{XN}-\mathrm{CF}(1: 1)$ \\
\hline Molecular formula & $\mathrm{C}_{24} \mathrm{H}_{24} \mathrm{~N} \mathrm{O}_{5.5}$ & $\mathrm{C}_{15.7} \mathrm{H}_{17} \mathrm{~N}_{0.3} \mathrm{O}_{4}$ & $\mathrm{C}_{44} \mathrm{H}_{49} \mathrm{~N} \mathrm{O}_{11}$ & $\mathrm{C}_{14.5} \mathrm{H}_{18} \mathrm{~N}_{2} \mathrm{O}_{4.5}$ \\
\hline Temperature (K) & $293(2)$ & $293(2)$ & $293(2)$ & $293(2)$ \\
\hline Crystal system & monoclinic & triclinic & triclinic & triclinic \\
\hline Space group & $P 21 / c$ & $P-1$ & $P-1$ & $P-1$ \\
\hline$a(\AA)$ & $19.754(2)$ & $10.2247(2)$ & $8.5254(3)$ & $6.979(2)$ \\
\hline$b(\AA)$ & $14.8652(8)$ & $14.3115(2)$ & $15.2889(4)$ & $13.470(3)$ \\
\hline$c(\AA)$ & $7.9105(7)$ & $16.0277(2)$ & $16.7199(9)$ & $16.775(2)$ \\
\hline$\alpha\left(^{\circ}\right)$ & 90 & $73.358(2)$ & $105.91(2)$ & $78.13(2)$ \\
\hline$\beta\left(^{\circ}\right)$ & $100.365(7)$ & $77.099(2)$ & 104.078(1) & 86.33(2) \\
\hline$\gamma\left({ }^{\circ}\right)$ & 90 & $75.304(2)$ & 93.564(1) & $77.82(2)$ \\
\hline$V\left(\AA^{3}\right)$ & $2284.9(3)$ & $2144.71(7)$ & 2013.4(2) & $1508.1(5)$ \\
\hline$Z$ & 4 & 6 & 2 & 4 \\
\hline Calculated density $\left(\mathrm{g} \mathrm{cm}^{-3}\right)$ & 1.2047 & 1.2726 & 1.267 & 1.287 \\
\hline Absorption coefficient $\left(\mathrm{mm}^{-1}\right)$ & 0.703 & 0.753 & 0.745 & 0.803 \\
\hline$F(000)$ & 879 & 875 & 816 & 622 \\
\hline$\theta$ range for data collection $\left(^{\circ}\right)$ & $3.74-68.87$ & $3.83-68.65$ & 3.49-83.19 & $3.92-66.53$ \\
\hline \multirow[t]{3}{*}{ Index ranges } & $-23 \leq \mathrm{h} \leq 23$ & $-12 \leq \mathrm{h} \leq 12$ & $-10 \leq \mathrm{h} \leq 10$ & $-8 \leq \mathrm{h} \leq 5$ \\
\hline & $-16 \leq \mathrm{k} \leq 17$ & $-16 \leq \mathrm{k} \leq 17$ & $-18 \leq \mathrm{k} \leq 18$ & $-16 \leq \mathrm{k} \leq 16$ \\
\hline & $-9 \leq 1 \leq 9$ & $-19 \leq 1 \leq 19$ & $-20 \leq 1 \leq 20$ & $-21 \leq 1 \leq 20$ \\
\hline \multirow[t]{2}{*}{ Reflections collected/unique } & $17962 / 4158$ & 39207/12487 & $32035 / 7314$ & $9599 / 5911$ \\
\hline & $\left(\mathrm{R}_{\mathrm{int}}=0.0554\right)$ & $\left(\mathrm{R}_{\mathrm{int}}=0.0306\right)$ & $\left(\mathrm{R}_{\mathrm{int}}=0.0332\right)$ & $\left(\mathrm{R}_{\mathrm{int}}=0.1580\right)$ \\
\hline Observed/restraints/parameters & $17504 / 0 / 341$ & $12487 / 3 / 1320$ & $7314 / 0 / 658$ & $5887 / 0 / 359$ \\
\hline Goodness-of-fit on $F^{2}$ & 0.993 & 1.007 & 1.090 & 1.2648 \\
\hline \multirow[t]{2}{*}{ Final $\mathrm{R}$ indices $(\mathrm{I}>2 \operatorname{sigma}(\mathrm{I}))$} & $\mathrm{R} 1=0.0637$ & $\mathrm{R} 1=0.0391$ & $\mathrm{R} 1=0.0497$ & $\mathrm{R} 1=0.2690$ \\
\hline & $w R 2=0.1801$ & $\mathrm{wR} 2=0.1077$ & $\mathrm{wR} 2=0.1510$ & $w R 2=0.5663$ \\
\hline \multirow[t]{2}{*}{$\mathrm{R}$ indices (all data) } & $\mathrm{R} 1=0.0985$ & $\mathrm{R} 1=0.0514$ & $\mathrm{R} 1=0.0546$ & $\mathrm{R} 1=0.4224$ \\
\hline & $w R 2=0.2183$ & $\mathrm{wR} 2=0.1188$ & $\mathrm{wR} 2=0.1570$ & $\mathrm{wR} 2=0.6645$ \\
\hline Largest diff. peak and hole $\left(\mathrm{e} \AA^{-3}\right)$ & $0.256 /-0.231$ & $0.157 /-0.142$ & $0.27 /-0.26$ & $0.89 /-0.60$ \\
\hline CCDC Number & 1955269 & 1955276 & 1955279 & 1955267 \\
\hline
\end{tabular}

\subsection{Single Crystal X-ray Diffraction}

\subsubsection{XN Molecule in Cocrystals}

The A ring and the $\alpha, \beta$-unsaturated carbonyl group adopt almost a planar conformation in all cocrystal structures due to the intramolecular hydrogen bond $\mathrm{O} 3 \mathrm{~A}-\mathrm{H} 3 \mathrm{~A} \cdots \mathrm{O} 2 \mathrm{~A}$. The $\mathrm{B}$ ring is rotated with a dihedral angle of $1-10^{\circ}$ with regard to the double bond plane. A planar conformation of the $\mathrm{B}$ ring is related to the intermolecular interactions in the crystal net. Rotations of the prenyl group around the $\mathrm{C} 16-\mathrm{C} 12$ bond are minor in all structures (see Figure 3). This is evident because the prenyl group interacts weakly with the surrounding atoms as it is visible in the large displacement ellipsoids of its atoms. In all cases the prenyl groups fill the gaps between planar parts in the $\mathrm{XN}$ molecules in the crystal lattices.

(a)

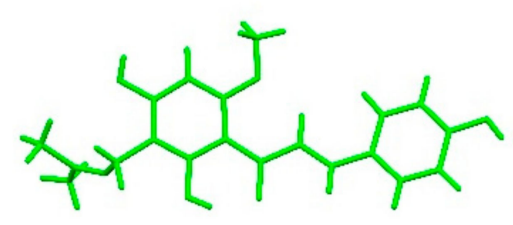

(b)

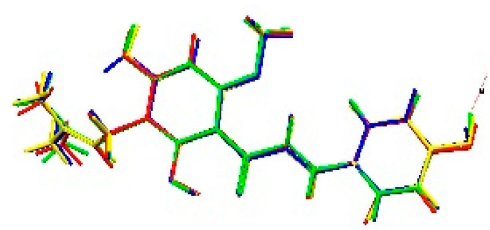

Figure 3. Cont. 


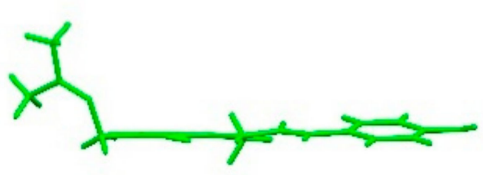

(c)
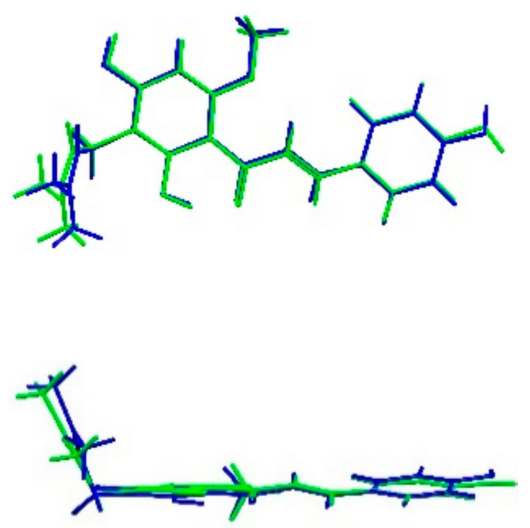

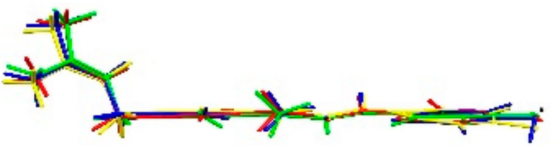

(d)
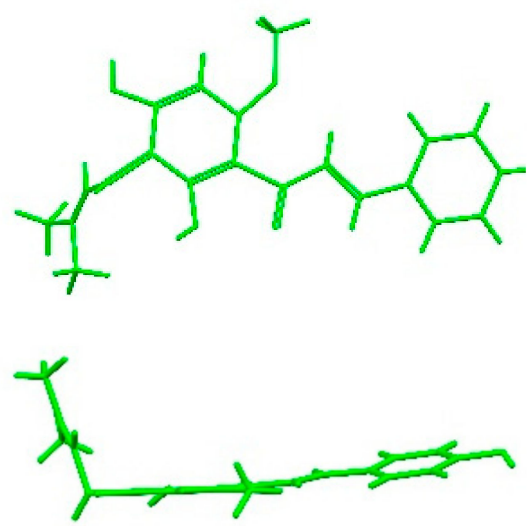

Figure 3. Side and top views of the $\mathrm{XN}$ molecules in (a) XN-NIC, (b) XN-GA, (c) XN-AC, and (d) XN-CF.

The most characteristic hydrogen bond motif in the structures of $\mathrm{XN}-\mathrm{NIC}, \mathrm{XN}-\mathrm{GA}$, and $\mathrm{XN}-\mathrm{AC}$ is between the $\mathrm{O} 4-\mathrm{H} 4 \mathrm{a}$ hydroxyl group and the $\mathrm{O} 2$ carbonyl oxygen originating from the neighboring $\mathrm{XN}$ molecule (Figure 4). This is the strongest hydrogen bond (1.64-1.92 $\AA$ ) between XN molecules observed in these cocrystals and it is responsible for the XN layers' stabilization in all cases. This hydrogen bond is the main building block of infinite chain $\mathrm{C}(8)$ (graph set notation). The structure of $\mathrm{XN}-\mathrm{CF}$ in this case is an exception because the $\mathrm{O} 2, \mathrm{O} 3$, and $\mathrm{O} 4$ oxygen atoms (A ring) form hydrogen bonds with caffeine. This molecular arrangement leads to the rather weak $\mathrm{XN}$ interlayer hydrogen bond interactions as well as the $\pi-\pi$ stacking resulting in the crystal cracking, and a low quality of the $\mathrm{XN}-\mathrm{CF}$ structure (Table 1). In all cases due to a steric hindrance, the O5 does not participate in any intermolecular hydrogen bonds. The hydroxyl group $\mathrm{O} 3 \mathrm{H} 3$ takes part in the intramolecular hydrogen bond to the $\mathrm{O} 2$ making $\mathrm{XN}$ molecular fragment more rigid and flat with all the $\mathrm{OH}$ moieties located on the plane (Figure 4 ).

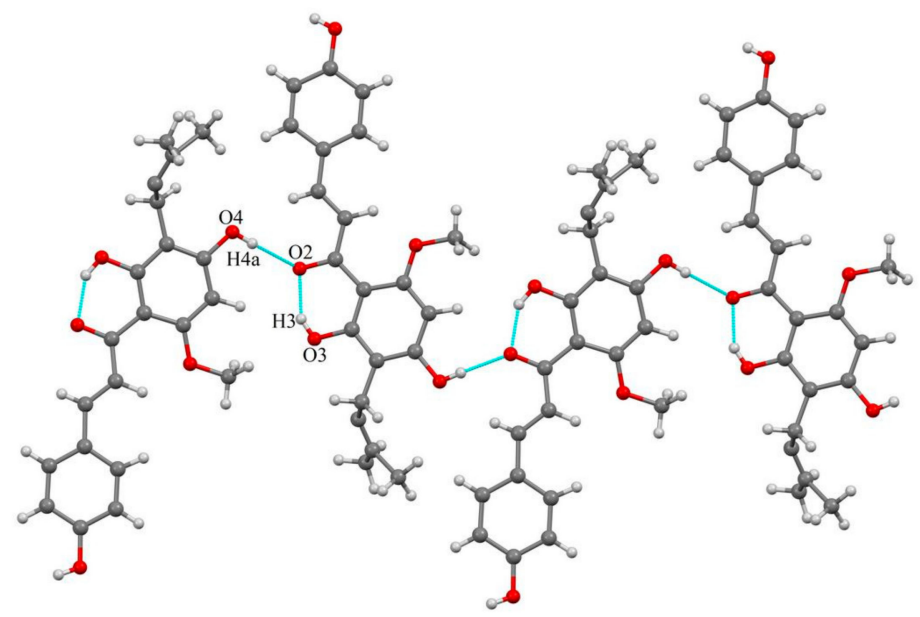

Figure 4. A layered section of the $\mathrm{XN}$ structure to show the homomolecular motif of infinite chains $\mathrm{C}(8)$ observed in the layers of $\mathrm{XN}$ molecules for the $\mathrm{XN}-\mathrm{NIC}, \mathrm{XN}-\mathrm{GA}$, and $\mathrm{XN}-\mathrm{AC}$ crystals. 


\subsubsection{Host-Coformer Interactions}

The O1-H1a hydroxyl group participates in synthon formation with coformers in all cases (Figure 5). This hydrogen bond provides the main driving force for cocrystallization in all presented structures. Moreover, only the $\mathrm{O}-\mathrm{H} \cdots \mathrm{O}, \mathrm{O}-\mathrm{H} \cdots \mathrm{N}$, and $\mathrm{N}-\mathrm{H} \cdots \mathrm{O}$ hydrogen-bonded interactions observed between the $\mathrm{XN}$ and coformer molecules were taken into account. The repeated heteromolecular motifs are presented in Figure 5.

a)

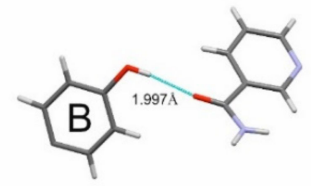

b)

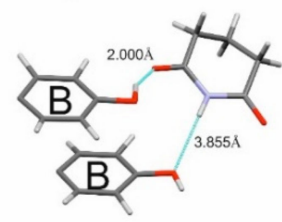

c)
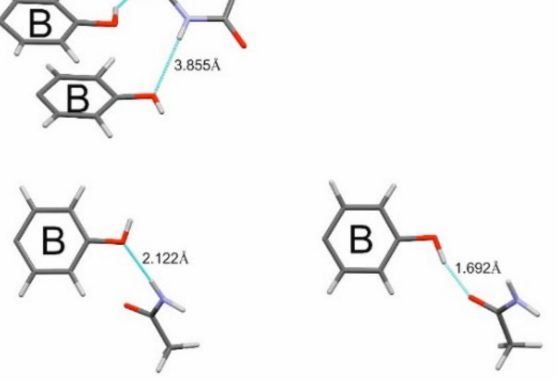

d)

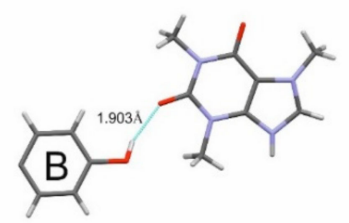

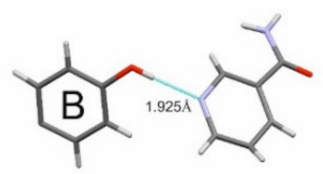

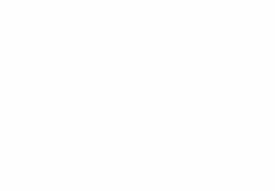

Figure 5. Supramolecular motifs observed in (a) XN-NIC, (b) XN-GA, (c) XN-AC, and (d) XN-CF.
The hydroxyl group O1-H1 from the B ring is hydrogen bonded with coformers in all studied structures.

In the case of XN-NIC, the XN molecule forms a synthon with carbonyl oxygen from nicotinamide molecule $(1.997 \AA)$ and nitrogen from the heterocyclic ring $(1.925 \AA)$ (Figure 5a). In the case of glutarimide the para hydroxyl group from the $B$ ring forms two hydrogen bonds with oxygen $(2.000 \AA)$ and the amine group (3.855 $\AA$ ) from the glutarimide molecule (Figure $5 b$ ). The small acetamide molecule adopts the optimal orientation to form two hydrogen bonds: the strongest one through carboxyl oxygen with the hydroxyl group from XN $(1.692 \AA)$ and weaker one with the $\mathrm{O} 2$ from the second neighboring $\mathrm{XN}$ molecule via the nitrogen atom (2.122 $\AA$ ) (Figure $5 \mathrm{c}$ ). Also, in $\mathrm{XN}-\mathrm{CF}$ the main synthon is formed through the hydrogen bond from the para hydroxyl group (O1-H1a) to the carbonyl oxygen from caffeine (1.903 $\AA$ ). In the structures $\mathrm{XN}-\mathrm{NIC}, \mathrm{XN}-\mathrm{GA}$, and $\mathrm{XN}-\mathrm{AC}$, the coformer molecules form infinite chains of hydrogen bonds in and out of the plane of XN layers (Figures 6-9).

\subsection{3. $\mathrm{XN}-\mathrm{NIC}(1: 1)$}

The asymmetric unit comprises one $\mathrm{XN}$ molecule and one nicotinamide molecule which is in the center of symmetry. In the crystal packing nicotinamide molecules form a columnar assembly in the $c$ direction which passes through the layers of XN molecules (Figure 6a). The distance between the XN layers is $\sim 3.55 \AA$. The nicotinamide molecules in chains are connected through hydrogen bonds between $\mathrm{O}$ and $\mathrm{N}$ atoms from the amide moiety. Moreover, the nicotinamide and $\mathrm{XN}$ molecules are bonded by the $\mathrm{C}(6)$ infinite hydrogen chain in the plane of $\mathrm{XN}$ molecules (Figure $6 \mathrm{~b}$ ). The stabilization of the three-dimensional crystal lattice structure is further provided by the hydrogen $\mathrm{XN}-\mathrm{XN}$ interactions as described earlier. 


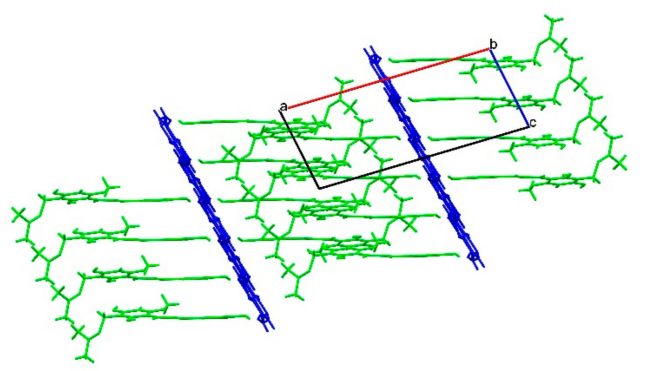

(a)

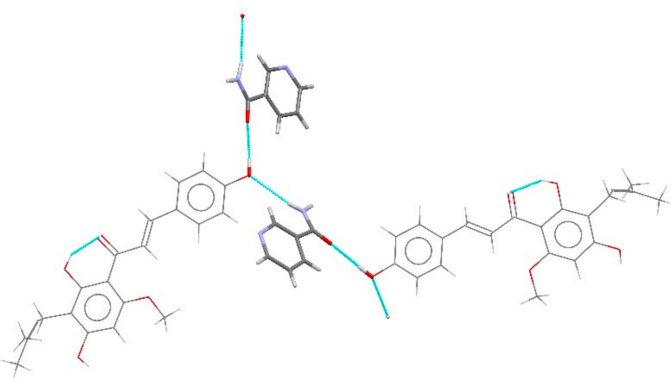

(b)

Figure 6. Crystal packing and interactions in the $\mathrm{XN}-\mathrm{NIC}$ cocrystal showing (a) a layered section of $\mathrm{XN}$ structure and nicotinamide columns crossing them and (b) an infinite hydrogen bond chain $\mathrm{C}(6)$ in the XN-NIC cocrystal.

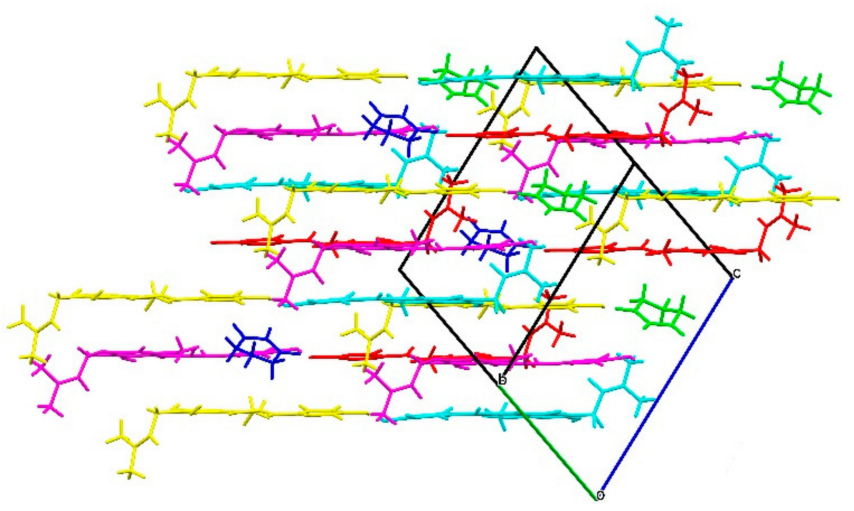

(a)

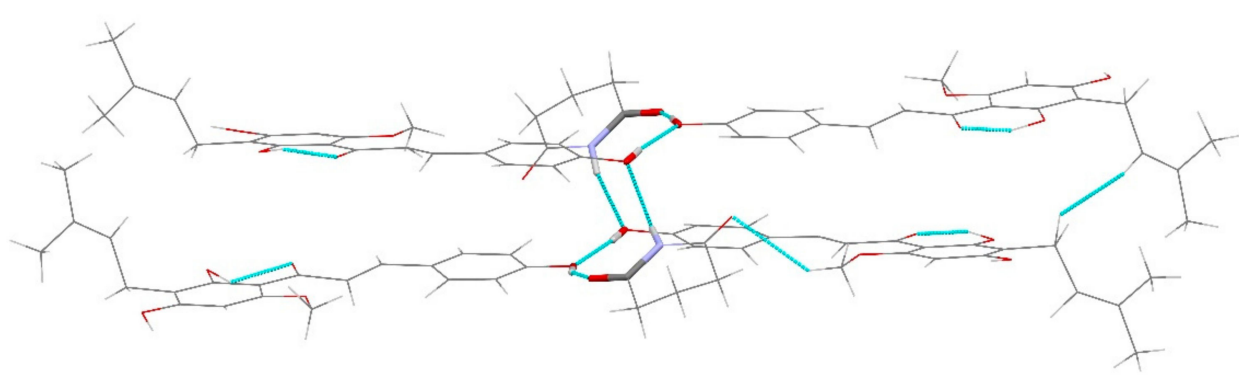

(b)

Figure 7. (a) Altered layers of $\mathrm{AD}, \mathrm{BC}$ (yellow A, magenta $\mathrm{D}$, red $\mathrm{B}$ and violet $\mathrm{C}$ ) of $\mathrm{XN}$ molecules in $\mathrm{XN}-\mathrm{GA} ;(\mathbf{b})$ hydrogen bonds in a supramolecular ring structure, the graph set notation $\mathrm{R}_{6}^{6}(16)$. No symmetrically equivalent $\mathrm{XN}$ molecules in the crystal structure are represented by different colors. 


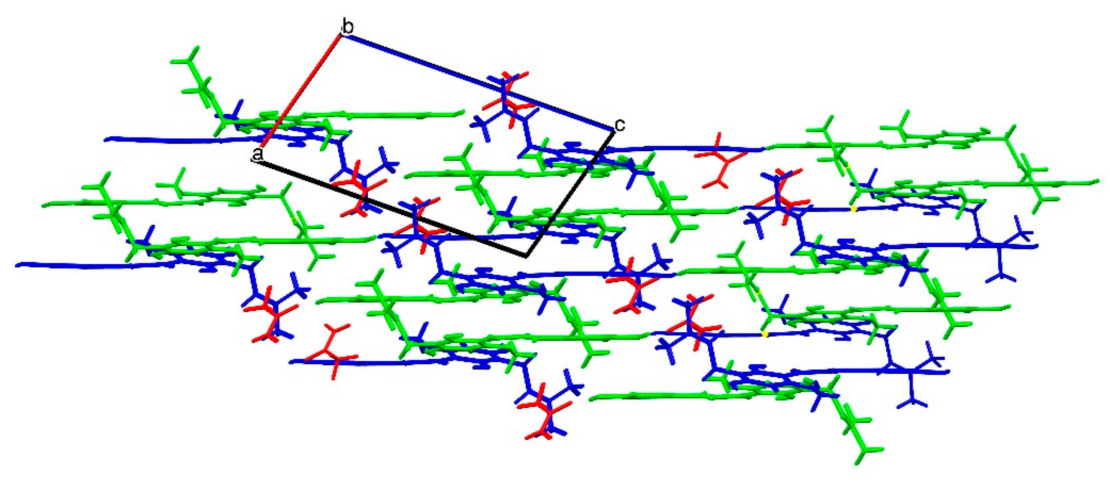

(a)

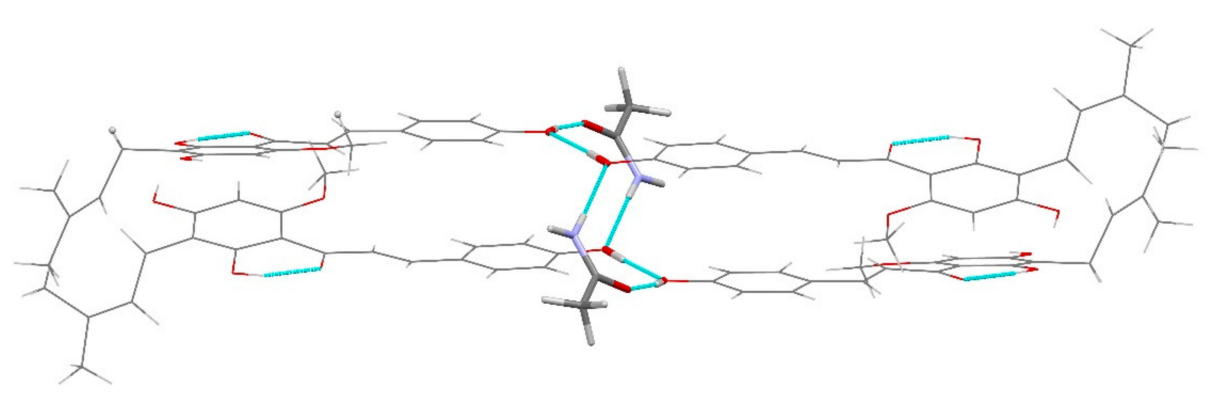

(b)

Figure 8. (a) Layers composed of A (blue) XN and B (green) XN molecules bonded by acetamide (red); (b) XN layers linking the $\mathrm{R}_{6}^{6}(16)$ supramolecular rings.

\subsubsection{XN-GA (1:1)}

The $\mathrm{XN}$ molecules are packed in the crystal net in the altered layers of $\mathrm{AD}, \mathrm{BC}$ arrangement (Figure 7a). Glutarimide molecules bind the AD and BC XN layers by the supramolecular hydrogen bonds ring $\mathrm{R}_{6}^{6}(16)$ (graph set notation, Figure $7 \mathrm{~b}$ ). The $\mathrm{XN}$ molecules are stabilized in the layers by the hydrogen bonds described above. In this structure the $\pi-\pi$ stacking interactions play a secondary role in layer binding.

\subsection{5. $\mathrm{XN}-\mathrm{AC}(1: 1)$}

The asymmetric unit cell is composed of two $\mathrm{XN}$ molecules and one acetamide molecule. The neighboring $\mathrm{XN}$ layers are bonded by supramolecular hydrogen bonds between the hydroxyl groups from the $\mathrm{XN}$ molecules (B rings) and acetamide (Figure 8). Similar to $\mathrm{XN}-\mathrm{GA}$, the $\mathrm{R}_{6}^{6}(16)$ supramolecular ring is also formed. In this structure stacking interactions between the rings play a minor role as compared to that of other cocrystals.

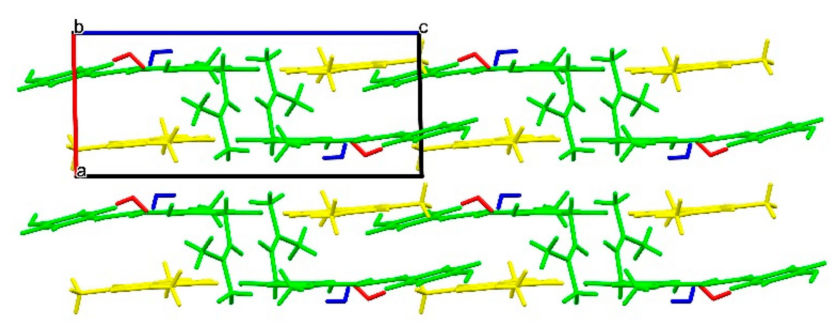

(a)

Figure 9. Cont. 


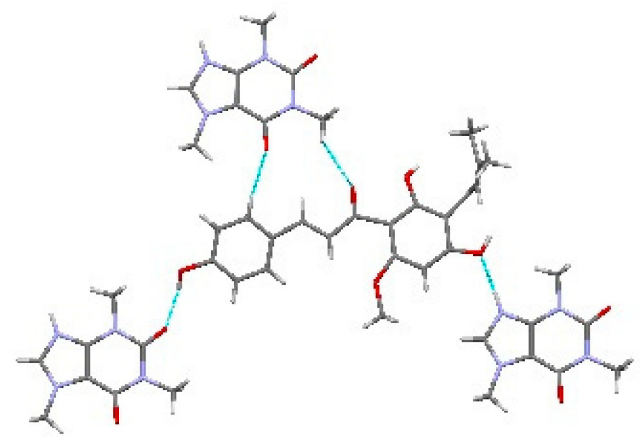

(b)

Figure 9. (a) Weakly bonded layers in the XN-CF cocrystals; (b) the in-plane of the $\mathrm{XN}$ layer hydrogen bonds. It can be seen that one $\mathrm{XN}$ molecule (green) is surrounded by three caffeine moieties (yellow).

\subsection{6. $\mathrm{XN}-\mathrm{CF}(1: 1)$}

This cocrystal consists of the $\mathrm{XN}$ molecule, caffeine, and two water molecules in the asymmetric part of the unit cell. In this case water is probably coming from atmosphere during crystallization. Similarly to the earlier described, this one consists of layers but both $\mathrm{XN}$ and caffeine molecules are in the same plane. The typical pattern of hydrogen bonds between the $\mathrm{XN}$ molecules observed for $\mathrm{XN}-\mathrm{NIC}, \mathrm{XN}-\mathrm{GA}$, and $\mathrm{XN}-\mathrm{AC}$ (Figure 4) is replaced by the net of $-\mathrm{XN}$-caffeine- $\mathrm{XN}$ - (Figure 9). The neighboring layers are bonded by the $\pi-\pi$ originating from the $\mathrm{XN}$ double bond electrons $(\mathrm{C} 8=$ C9) and a six-membered caffeine ring (Figure 9). This justifies the crystal tendency to be easily cleaved along the $\mathrm{XN}$-caffeine planes and poor crystal quality $\left(\mathrm{R}_{1}=29 \%\right)$. Water molecules are located in channels along $a$ direction and are planar with the layers. As the data quality is very poor, possible hydrogen bonds between the water and the $\mathrm{XN}$ or water-caffeine can only be approximated.

\subsection{Solubility Determination}

It has been reported that handling of xanthohumol is difficult since the poor solubility in water $\left(1.3 \mathrm{mg} / \mathrm{L}\right.$ at $23^{\circ} \mathrm{C}$ [2] $)$ is a major drawback in reproducibility results in the pharmacological studies both in vitro and in vivo [35]. In this way, the application of UV-Vis spectroscopy to compare the solubility of $\mathrm{XN}$ with its cocrystals was not possible in pure water, and therefore the solubility experiment was evaluated in a 50:50 (v/v) ethanol-water solution in accordance to similar cases $[36,37]$. Due to the relative high solubility of used coformers in aqueous media (several orders of magnitude higher than the value reported for $\mathrm{XN}$ ), it is suggested that the dissolution profile of $\mathrm{XN}$ would be improved after the cocrystals formation. The result of solubility determination of $\mathrm{XN}$ and its cocrystalline phases is presented in Figure 10. As expected, all cocrystals investigated exhibit the improvement of solubility, with the largest solubility enhancement demonstrated by the $\mathrm{XN}-\mathrm{AC}$ cocrystals, which is ca. 2.6 times greater as compared to intact $\mathrm{XN}$. The solubility curve of $\mathrm{XN}$ with the maximum solubility value of $7.6 \mathrm{mg} / \mathrm{L}$ subsequently reaches a plateau after $30 \mathrm{~min}$. It is shown that the solubility of $\mathrm{XN}$ is in the same range as determined by Stevens et al. with $3.5 \mathrm{mg} / \mathrm{L}$ (in $5 \%$ ethanol) [2]. However, the 'spring and parachute' effect described by Guzmán et al. [38], which is commonly observed in case of the enhanced solubility of drug cocrystals did not occur in the study reported herein. Finally, the solubility profiles of pure $\mathrm{XN}$ and its cocrystals revealed that the approach of cocrystallization with successful solubility modification was achieved with maximum solubilities of $9.98( \pm 0.58), 10.54( \pm 0.98), 12.73( \pm 0.67)$, and $20.07( \pm 0.70) \mathrm{mg} / \mathrm{L}$ demonstrated by the $\mathrm{XN}-\mathrm{CF}, \mathrm{XN}-\mathrm{NIC}$, $\mathrm{XN}-\mathrm{GA}$, and $\mathrm{XN}-\mathrm{AC}$ cocrystals, respectively. 


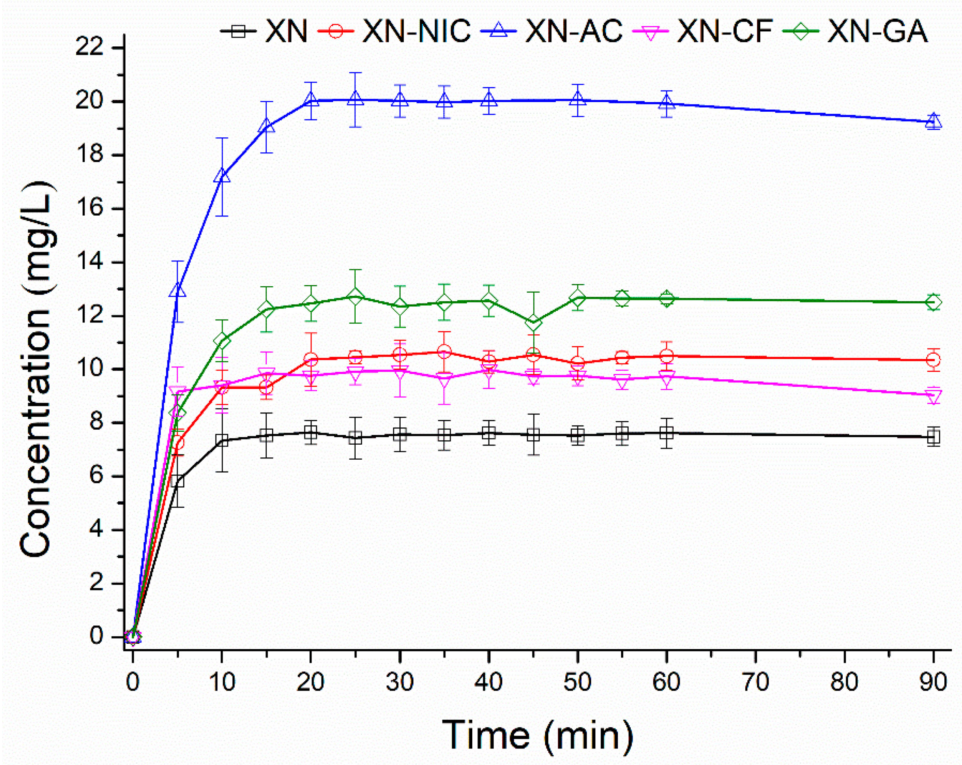

Figure 10. Solubility profiles of $\mathrm{XN}$ and its cocrystals $(\mathrm{XN}-\mathrm{CF}, \mathrm{XN}-\mathrm{NIC}, \mathrm{XN}-\mathrm{GA}$, and $\mathrm{XN}-\mathrm{AC})$ in a 50:50 (v/v) ethanol-water solution at $27^{\circ} \mathrm{C}$.

\subsection{Vibrational Spectroscopy}

A more profound insight into the $\mathrm{XN}$ cocrystal phenomena was obtained through vibrational spectroscopy. The above discussed results are supported by trends in the infrared absorption and Raman spectra. The FTIR and Raman spectra for all of the discussed cocrystals and assignment of specific vibration modes based on the studies carried out for individual components are collected in Figures S4 and S5 and Tables S1 and S2, whereas the spectra of target cocrystals are presented in Figures 11 and 12.

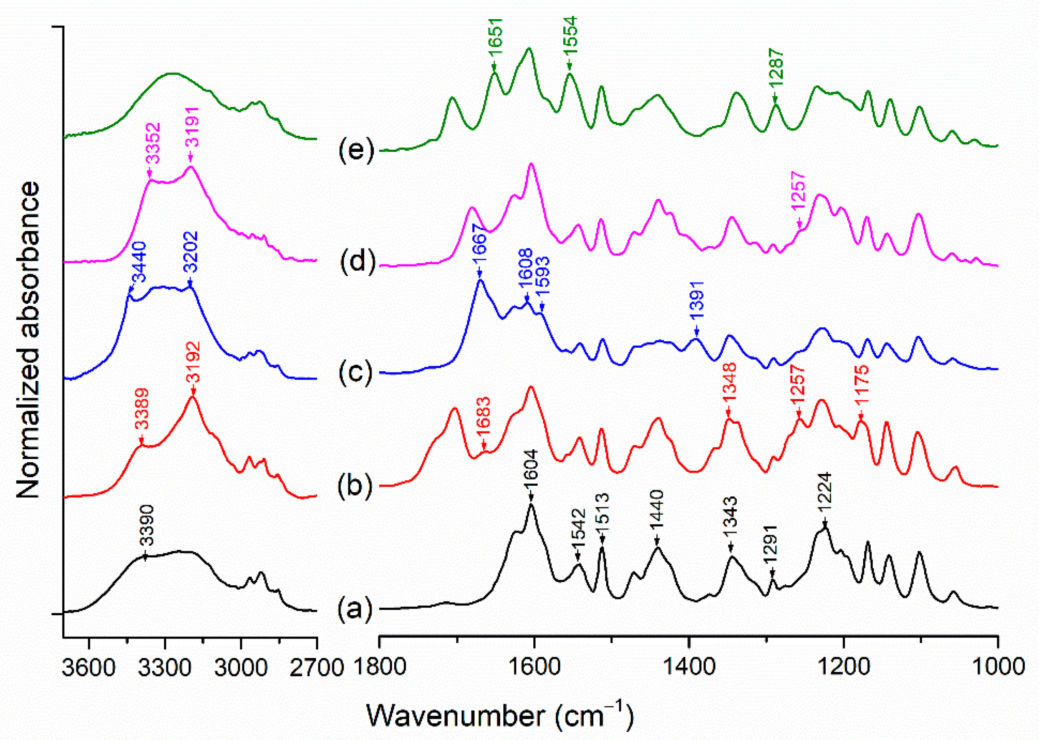

Figure 11. FTIR spectra of (a) xanthohumol, and the investigated cocrystals: (b) XN-GA, (c) XN-AC, (d) XN-NIC, and (e) XN-CF. 


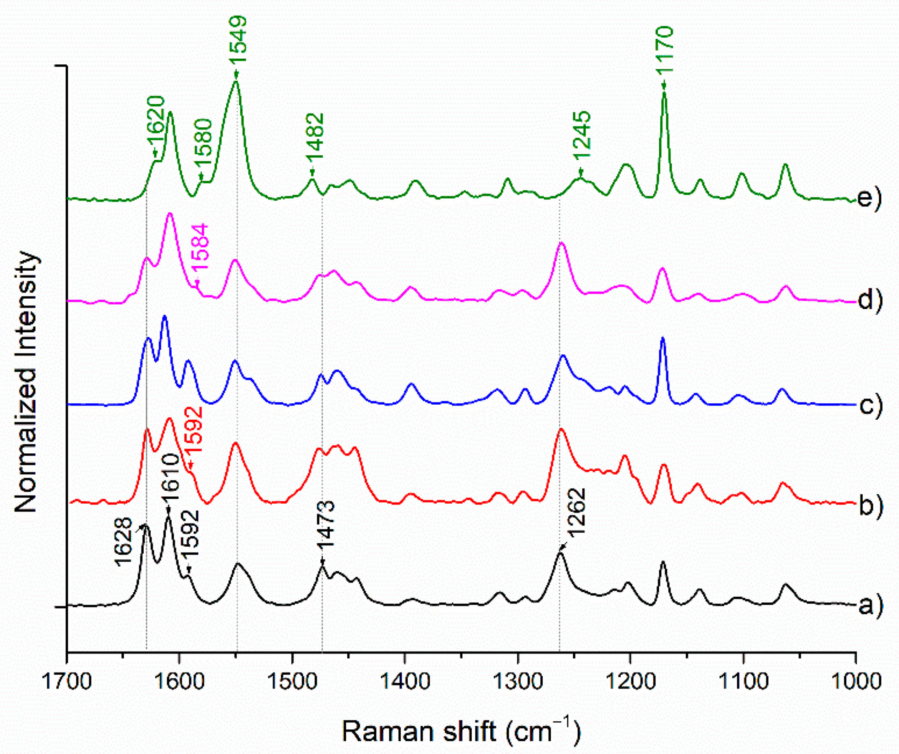

Figure 12. Raman spectra of (a) xanthohumol and the target cocrystals: (b) $\mathrm{XN}-\mathrm{GA},(\mathbf{c}) \mathrm{XN}-\mathrm{AC}$, (d) $\mathrm{XN}-\mathrm{NIC}$, and (e) $\mathrm{XN}-\mathrm{CF}$.

The experimental results show that the FTIR spectra of physical mixtures composed of XN with coformers revealed the linear combination of the bands specific to individual components and no significant shifts were observed, as shown in Figure S3. However, the infrared absorption spectra of the $\mathrm{XN}$ cocrystals are definitely differentiated from that of the physical mixture. As follows from Figure 11, there are characteristic changes in positions, relative intensities, and shapes of some vibrational peaks upon cocrystal formation. It has been indicated that in o-hydroxychalcones an intramolecular hydrogen bonding between the $\mathrm{OH}$ and the carbonyl oxygen atom exists [39]. As discussed above, the $\mathrm{O} 3 \mathrm{H} 3$ and $\mathrm{O} 4 \mathrm{H} 4$ groups in the $\mathrm{XN}$ molecule are involved in the intra- and intermolecular hydrogen bonding so the $\mathrm{O} 1 \mathrm{H} 1$ group can undergo hydrogen bonding in the $\mathrm{XN}$ cocrystal products easily (as indicated by the presented structures). On the other hand, the above analysis showed that in the structure of $\mathrm{XN}-\mathrm{CF}$, all hydroxyl groups from the $\mathrm{XN}$ molecule form hydrogen bonds with caffeine. These hydroxyl groups are applied to target the several groups in coformers such as the aromatic nitrogen and the amide groups (acetamide, nicotinamide), the nitrogen and carbonyl groups in the glutarimide ring (glutarimide) and the nitrogen in the imidazole ring (caffeine).

As a result, in the region $3500-3200 \mathrm{~cm}^{-1}$ corresponding to the stretching mode of $\mathrm{OH}$ groups, an increase in intensity and broadening of some bands are observed. In particular, the bands at $3440 \mathrm{~cm}^{-1}$ and $3202 \mathrm{~cm}^{-1}$ (XN-AC), $3389 \mathrm{~cm}^{-1}$ and $3192 \mathrm{~cm}^{-1}$ (XN-GA), and $3352 \mathrm{~cm}^{-1}$ and $3191 \mathrm{~cm}^{-1}$ (XN-NIC) were also shifted to lower or higher frequencies as compared to the starting materials. The exception are the $\mathrm{XN}-\mathrm{CF}$ cocrystals since only a broad band appeared in this region due to water molecules in the structure (Figure 11). A shift from $3160 \mathrm{~cm}^{-1}$ in the spectrum of acetamide to $3202 \mathrm{~cm}^{-1}$ in the cocrystal spectrum confirms the involvement of the amide group of AC in hydrogen bonding [28]. A new band at $3440 \mathrm{~cm}^{-1}$ was related to the presence of the $\mathrm{N}-\mathrm{H}$ stretching vibrations and the intermolecular $\mathrm{N}-\mathrm{H} \cdots \mathrm{O} 1$ interactions with the $\mathrm{XN}$ molecule. Similarly, such a spectral pattern was also distinguished in XN-NIC and XN-GA with a new band at $3352 \mathrm{~cm}^{-1}$ and $3389 \mathrm{~cm}^{-1}$, respectively, and upshift of band at ca. $3190 \mathrm{~cm}^{-1}$ in comparison to the pure coformers.

In the region of $1710-1520 \mathrm{~cm}^{-1}$, the FTIR spectra are dominated by the bands attributed to the ring $C=C$ stretching conjugated with the carbonyl group $(X N)$, the $C=O$ (all coformers), the amide $\mathrm{I}$, amide II bands (AC and NIC), and the $\mathrm{C}=\mathrm{N}$ stretching vibrations ( $\mathrm{CF}$ and NIC) [40-44]. The intensity of absorption of isolated carbonyls in the $\mathrm{XN}-\mathrm{CF}$ cocrystals remains almost constant (ca. $1704 \mathrm{~cm}^{-1}$ ), while the band assigned to a conjugated carbonyl group $\left(1660 \mathrm{~cm}^{-1}\right)$ is shifted toward lower frequencies as a result of this mode envelopment in hydrogen bonding [43]. The peak at $1681 \mathrm{~cm}^{-1}$ due to the 
$-\mathrm{C}=\mathrm{O}$ mode of amide moiety of acetamide shifts to $1667 \mathrm{~cm}^{-1}$ in the cocrystal demonstrating its involvement in the hydrogen bonding in the cocrystal structure. Interestingly, the $\mathrm{C}=\mathrm{O}$ amide moiety vibrations of NIC were registered at the same position in the XN-NIC cocrystals indicating that the force constants of the synthons are not strongly changed upon formation of this cocrystal [45]. The intense band in the spectra of all cocrystals centered at $1624 \mathrm{~cm}^{-1}$, contributed probably by $\mathrm{C}=\mathrm{O}$ involved in the intramolecular hydrogen bonding and $\mathrm{C}=\mathrm{C}$ stretching modes in the $\mathrm{XN}$ molecules remains almost unaffected upon cocrystallization. A similar situation refers to two other bands at 1542 and $1513 \mathrm{~cm}^{-1}$, assigned to $\mathrm{OH}$ bending and $\mathrm{C}-\mathrm{C}$ ring stretching, except for the $\mathrm{XN}-\mathrm{CF}$ cocrystal when a broad band centered at $1554 \mathrm{~cm}^{-1}$. It is shifted toward higher frequencies as compared to pure caffeine. In the region of the $\mathrm{C}-\mathrm{OH}$ in-plane bending vibrations a new band appeared at $1391 \mathrm{~cm}^{-1}$ in the $\mathrm{XN}-\mathrm{AC}$ spectrum which was shifted to lower wavenumbers compared to the position in pure acetamide. This band is associated with the vibrational frequencies for the $\mathrm{C}-\mathrm{N}$ stretch and $\mathrm{N}-\mathrm{H}$ bends, and the shift of its position confirms the interactions between these groups of $\mathrm{XN}$ and acetamide. It is obvious that in the region of bending vibrations of $\mathrm{C}-\mathrm{OH}$ (phenyl ring), the most significant changes should be revealed for the $\mathrm{XN}-\mathrm{CF}$ cocrystals due to participation of all hydroxyl groups from $\mathrm{XN}$ in the intermolecular interactions. Indeed, the intense band at $1343 \mathrm{~cm}^{-1}$ attributed to $8 \mathrm{OH}$ in XN is downshifted by $5 \mathrm{~cm}^{-1}$ in the spectrum of the $\mathrm{XN}-\mathrm{CF}$ cocrystals. There is also a simultaneous shift of band located at $1291 \mathrm{~cm}^{-1}$ in the XN spectrum to $1287 \mathrm{~cm}^{-1}$ in the XN-CF cocrystals.

In general, the strong bands in the FTIR spectrum of a compound correspond to the weak bands in the Raman spectrum. On the other hand, large variations of both the molecular dipole moment and molecular polarizability may be induced by the intramolecular charge transfer between the carbonyl group and phenyl ring through the ethylenic bridge in the XN molecule, then making IR and Raman activity strong simultaneously [46].

The comparison of the Raman spectra of target cocrystals and the starting materials showed the spectra to differ distinctly in the $\mathrm{C}=\mathrm{C}$ and $\mathrm{C}=\mathrm{O}$ stretching region. It can be seen from Figure 12 that the vibrational modes of $\mathrm{XN}$ (in the form of single crystal) in the spectra range $1700-1520 \mathrm{~cm}^{-1}$ have strong bands in both Raman and FTIR spectra at the same time. Except for one exception (XN-CF, Figure 12e), the intense bands at $1628 \mathrm{~cm}^{-1}$ and $1610 \mathrm{~cm}^{-1}$ are slightly shifted toward lower frequencies in the Raman spectra of cocrystals. Moreover, the ratio of these intensities, to a large extent, remains constant only for the $\mathrm{XN}-\mathrm{GA}$ cocrystal. Additionally, in the region discussed above, the spectrum of the $\mathrm{XN}-\mathrm{GA}$ cocrystal has the most broadened bands which is related to the six different arrangements of $\mathrm{XN}$ molecules in an asymmetric part of the unit cell. For other cocrystals an increase in the intensity of the band at ca. $1628 \mathrm{~cm}^{-1}$ in favor of the second one is observed. This effect is observed in the case of the $\mathrm{XN}-\mathrm{CF}$ cocrystal, and the downshift of this band is the largest (by $8 \mathrm{~cm}^{-1}$ ) with a parallel increase in the intensities of two bands at 1549 and $1170 \mathrm{~cm}^{-1}$. This can be explained by the fact that in the molecular arrangement of $\mathrm{XN}-\mathrm{CF}$ there are both weak $\mathrm{XN}$ interlayer hydrogen bond interactions and $\pi-\pi$ stacking. This can be also seen in the region of bending vibrations of the phenyl ring of $\mathrm{XN}$ since two intensive bands at about 1470 and $1260 \mathrm{~cm}^{-1}$ are not present in the spectrum of $\mathrm{XN}-\mathrm{CF}$.

\subsection{Multivariate Analysis}

\subsubsection{Principal Component Analysis (PCA)}

The restrictions of vibrational spectroscopy due to overlapping bands coming from individual components in the spectra of cocrystals mean that a supplementary tool for cocrystals detection should dispel any doubts. There are various examples of taking advantage of a chemometric approach in the interpretation of the obtained results from the spectroscopy measurements [47-50]. To gain a more profound insight into the discrimination of physical mixtures with coformers and cocrystals, principal component analysis based on the FTIR and Raman spectra was performed. The contribution of the principal components is shown in Table 2. The first three principal components explain more than $84.5 \%$ of the total variance (structure of dependence of primary variables) in all cases. Based on the 
scree plot (Figure S6a-c) representing the graphic relationship between the eingenvalues and principal components (PCs), three main components were used for further analysis.

Table 2. Eigenvalues, percentage of variance, and cumulative percentage in the data used for the PCA calculations obtained for the XN cocrystals and the physical mixtures (only for the FTIR data).

\begin{tabular}{ccccc}
\hline Raman Spectra & Principal Component Number & Eigenvalue & Percentage of Variance (\%) & Cumulative (\%) \\
\hline $1700-1000 \mathrm{~cm}^{-1}$ & 1 & 5.452366 & 61.78255 & 61.7826 \\
& 2 & 2.476297 & 28.05973 & 89.8423 \\
& 3 & 0.656420 & 2.71961 & 100.0000 \\
\hline FTIR Spectra & Principal Component Number & Eigenvalue & Percentage of Variance (\%) & Cumulative (\%) \\
\hline $3700-2700 \mathrm{~cm}^{-1}$ & 1 & 1.354704 & 58.52862 & 58.5286 \\
& 2 & 0.601572 & 25.99032 & 84.5189 \\
& 3 & 0.238949 & 10.32354 & 94.8425 \\
& 4 & 0.073795 & 3.18824 & 98.0307 \\
\hline $1800-1000 \mathrm{~cm}^{-1}$ & 1 & 3.506911 & 52.04774 & 52.0477 \\
& 2 & 1.439899 & 21.37023 & 73.4180 \\
& 3 & 0.749832 & 11.12861 & 84.5466 \\
& 4 & 0.601722 & 3.93044 & 93.4770 \\
& 5 & 0.208369 & 1.75435 & 98.3695 \\
\end{tabular}

Raman Spectroscopy

Figure 13 presents the PCA score plot of PC1 vs. PC2 showing the significant cumulative percentage of total variance $(90 \%)$. PC1 represents $61.78 \%$ of the explained variance and PC2 accounts for $28.06 \%$. These two components distinguish the three groups. The XN-AC and XN-NIC cocrystals and $\mathrm{XN}$ create a cluster at the top of the left hand side of the plot and correlate negatively with PC1 and positively with PC2 while XN-CF and XN-GA are separated from others and create two different clusters. The other combinations of the first three PCs (PC1 vs. PC3 and PC2 vs. PC3) are presented in Figure S7a,b. The addition of the third principal component (7.43\% of total variance) facilitates discrimination between the cocrystals and the crystal form of $\mathrm{XN}$, especially between the XN-NIC and $\mathrm{XN}-\mathrm{AC}$ cocrystals. The PC1, PC2, and PC3 loading values for the analyzed region of the Raman spectra are presented in Figure S8. The highest values of the loading plot are located in the 1628-1550 and $1262-1170 \mathrm{~cm}^{-1}$ regions. It is worth noting that there is a correlation between the PCA score plot and the loading values [50]. The observations which are positively correlated with PC1 in the score plot have positive peaks on the PC1 loading plot, and vice versa. The peaks positively correlated with the PC1 loading factor describe XN-CF, and those negatively correlated with the PC1 loading factor delineate the other samples, respectively.

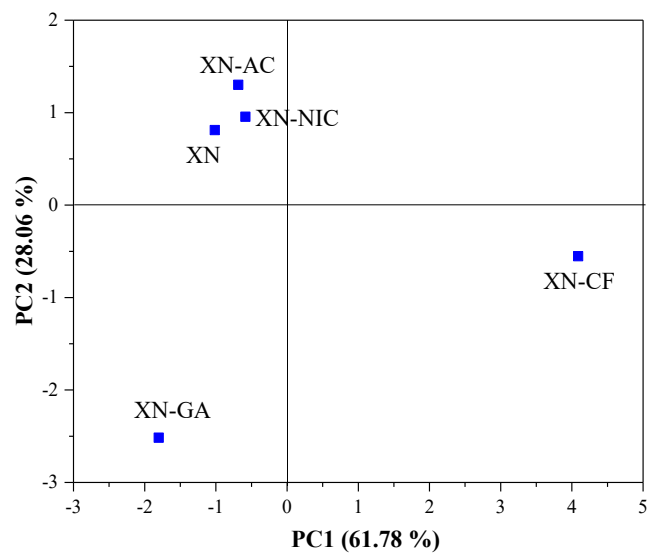

Figure 13. Principal component analysis (PCA) two-dimensional (2D) score plot (PC1 vs. PC2) calculated for the data acquired from the Raman spectra. 


\section{FTIR Spectroscopy}

In order to evaluate the main differences in the FTIR spectra, the PCA analysis was made for the two regions: $3700-2700 \mathrm{~cm}^{-1}$ and $1800-1000 \mathrm{~cm}^{-1}$ for $\mathrm{XN}$, the target cocrystals, and the physical mixtures composed of $\mathrm{XN}$ and coformers. In this case the contribution of the total variance to PC1 is $58.53 \%$ while PC2 accounts for a lower percentage of the total variance (26\%). The PCA score plots for the first two PCs are shown in Figure 14a. PC1 correlates positively with the $\mathrm{XN}, \mathrm{XN}-\mathrm{CF}$, $\mathrm{XN}-\mathrm{GA}, \mathrm{XN}-\mathrm{NIC}$, and $\mathrm{XN}-\mathrm{CF}_{\text {mix }}$ samples, but negatively with the $\mathrm{XN}-\mathrm{AC}$ cocrystals, and physical mixtures $\left(\mathrm{XN}-\mathrm{AC}_{\text {mix }}, \mathrm{XN}-\mathrm{GA}_{\text {mix }}\right.$, and $\left.\mathrm{XN}-\mathrm{NIC} \mathrm{C}_{\text {mix }}\right)$. The $\mathrm{XN}-\mathrm{NIC}, \mathrm{XN}-\mathrm{GA}$, and $\mathrm{XN}-\mathrm{CF}$ cocrystals are grouped closely to each other and form a cluster in the central part of the PCA score plot, except for $\mathrm{XN}-\mathrm{AC}$. Probably a new band $3440 \mathrm{~cm}^{-1}$ in the spectrum of $\mathrm{XN}-\mathrm{AC}$ can determine this separation. Noticeably, physical mixtures are located around cocrystals and are further separated from the center of the score plot. In the high wavenumber range, the $\mathrm{XN}$ sample shows insignificant similarities to the $\mathrm{XN}-\mathrm{CF}$ cocrystals. After the addition of the PC3 component (Figure S9a) which accounts for $10.32 \%$ of the total variance, it can be observed that the cocrystals and physical mixtures are distinctly separated and located in different positions. The loading plots for PC1, PC2, and PC3 are presented in Figure S9. This shows that the region between 3443 and $3180 \mathrm{~cm}^{-1}$ has a significant impact on the evaluation of similarities and differences between the samples.
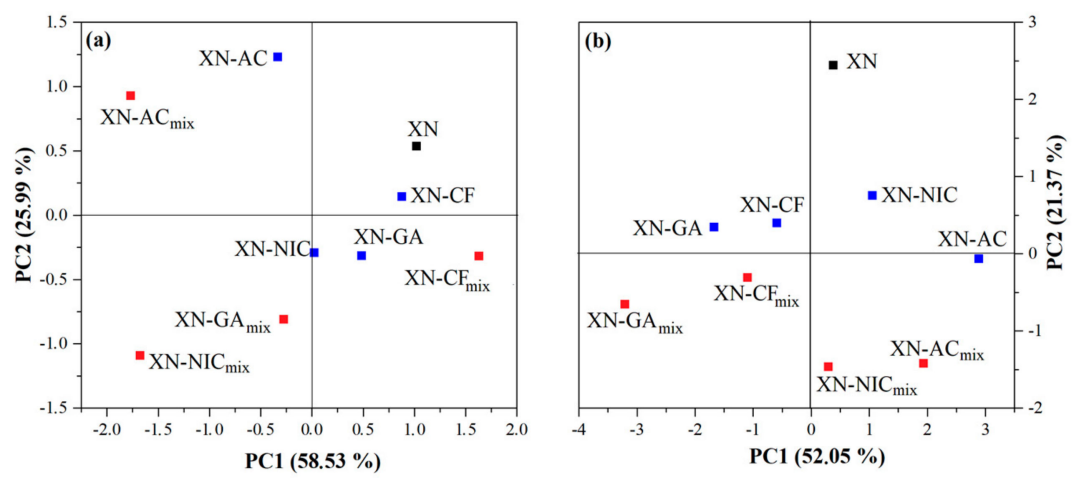

Figure 14. PCA 2D score plots (PC1 vs. PC2). (a) The region of 3700-2700 $\mathrm{cm}^{-1}$, and (b) the region of $1800-1000 \mathrm{~cm}^{-1}$ (red symbols represent the physical mixtures, blue symbols represent the cocrystals, and black symbols represent $\mathrm{XN}$ ).

In the fingerprint region, PC1 represents $52.05 \%$ and PC2 21.37\% of the total variance. The PCA score plots for the studied samples are shown in Figure 14b. It is observed that the $\mathrm{XN}, \mathrm{XN}-\mathrm{NIC}$, $\mathrm{XN}-\mathrm{AC}, \mathrm{XN}-\mathrm{NIC} \mathrm{mix}_{\text {mix }}$ and $\mathrm{XN}-\mathrm{AC}_{\text {mix }}$ samples are positively correlated with $\mathrm{PC} 1$ whereas $\mathrm{XN}-\mathrm{CF}$, $\mathrm{XN}-\mathrm{GA}, \mathrm{XN}-\mathrm{CF}_{\text {mix }}$, and $\mathrm{XN}-\mathrm{GA}_{\text {mix }}$ correlate negatively. Noticeably, in this spectral range PC2 is helpful to differentiate cocrystals (positively correlated) in physical mixtures (negatively correlated). However, the $\mathrm{XN}-\mathrm{AC}$ cocrystal is located in closer proximity to physical mixtures than other cocrystal samples. Yet most importantly, XN is clearly separated from other samples. As expected, the first two PCs allow cocrystals to be distinguished from pure $\mathrm{XN}$ and physical mixtures. The score plots for PC1 vs. PC3 and PC2 vs. PC3 are shown in Figure S10a,b. Loadings factors for the first three PCs are presented in Figure S11. The highest values of loadings are observed for the region of $1705-1553 \mathrm{~cm}^{-1}$ which are attributed to the $\mathrm{C}=\mathrm{C}, \mathrm{C}=\mathrm{O}$, and $\mathrm{C}=\mathrm{N}$ stretching vibrations.

\subsubsection{Hierarchical Clustering Analysis (HCA)}

Figure 15 presents the tree diagrams obtained from the hierarchical clustering analysis using the data acquired from the Raman and FTIR spectra in the same spectral range as the PCA analysis. The use of the complete linkage and average linkage methods of agglomeration gives similar results for the data presented in the Raman spectra (Figure 15a,b). The results are cut off at about 3 units of distance and form three clusters. The $\mathrm{XN}, \mathrm{XN}-\mathrm{NIC}$, and $\mathrm{XN}-\mathrm{AC}$ cocrystals create the first cluster 
(2.4 unit of distance) and display the largest similarity, whereas the XN-CF and XN-GA samples create two subsequent clusters (Figure 15a). This is similar to those found in the PCA score plot (Figure 13). In the other method the results are cut off at about 0.2 units of distance (Figure 15b). In this case, the first cluster is gradually formed by the XN, XN-NIC, XN-GA, and XN-AC cocrystals. Interestingly, the $\mathrm{XN}-\mathrm{CF}$ sample is grouped in a separate cluster in both methods.

a)

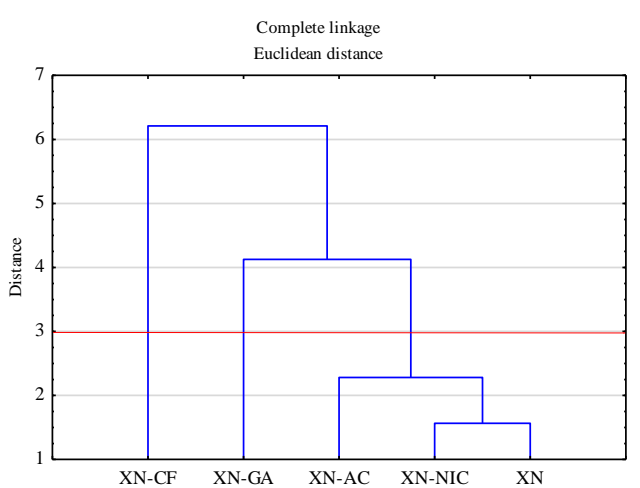

c)

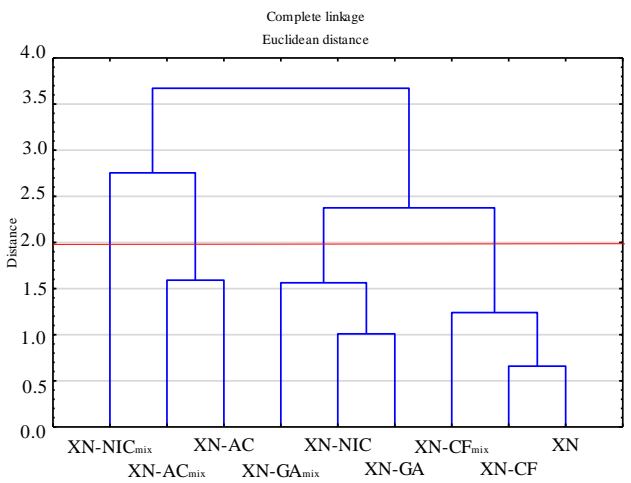

e)

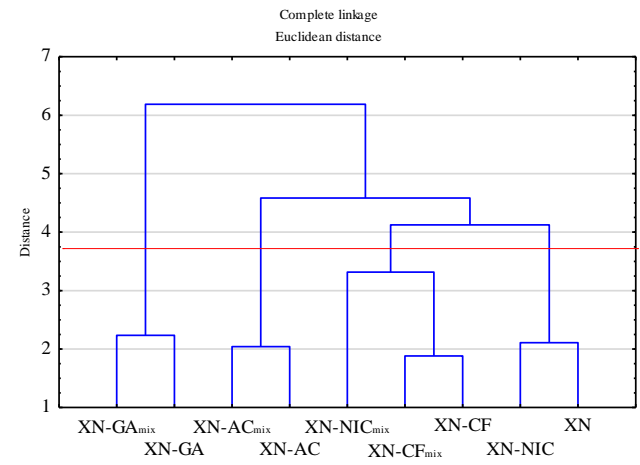

b)

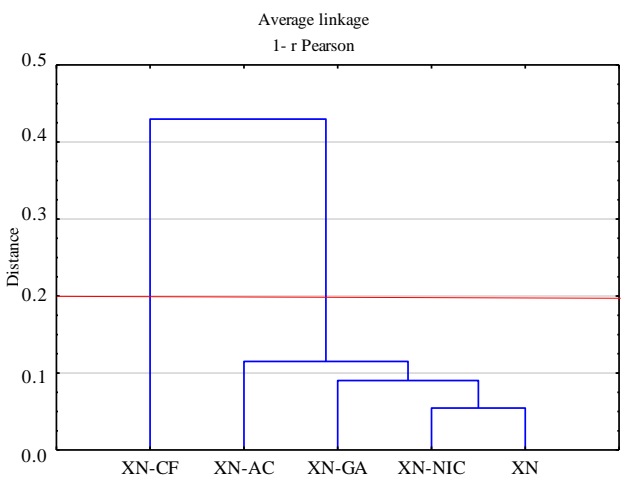

d)

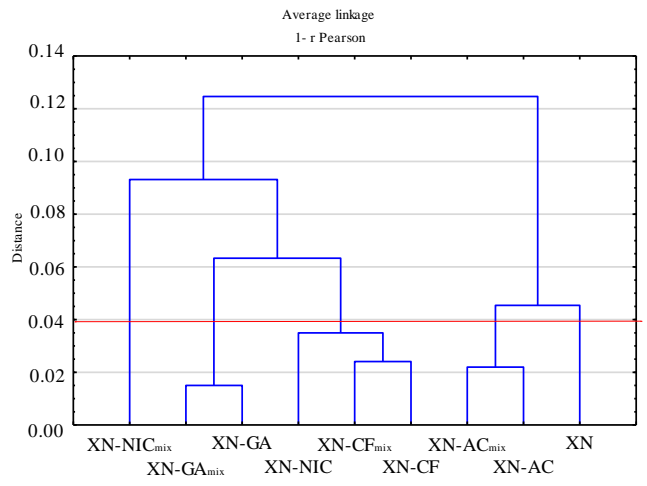

f)

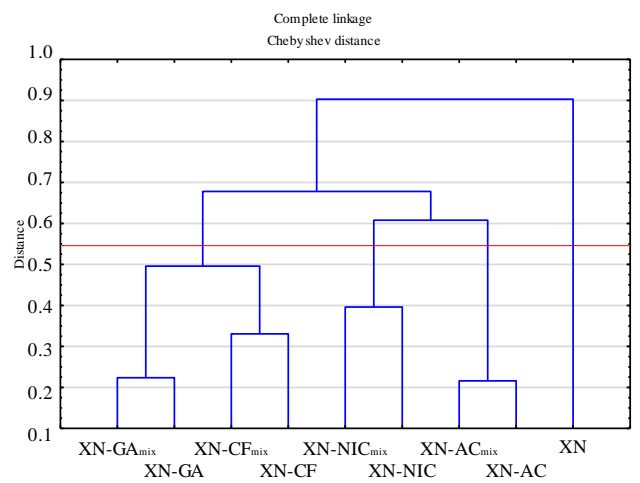

Figure 15. Hierarchical clustering analysis (HCA) tree diagrams for the data obtained from the $(\mathbf{a}, \mathbf{b})$ Raman, and (c,d) FTIR spectra in the regions of $3700-2700 \mathrm{~cm}^{-1}$ and $(\mathbf{e}, \mathbf{f}) 1800-1000 \mathrm{~cm}^{-1}$.

As shown in Figure 15c,d, HCA distributes the cocrystals and physical mixtures into four clusters. The $\mathrm{XN}$ and $\mathrm{XN}-\mathrm{CF}$ samples are grouped in the first cluster at the shortest distance which corresponds to the results from the PCA score plot presented in Figure 14a. The XN-NIC ${ }_{\text {mix }}$ sample creates a separate cluster which is the most distinct from the others. It should be noticed that the cocrystals and physical mixtures composed of the same conformer form individual clusters, except for the XN-NIC and $\mathrm{XN}-\mathrm{NIC}_{\text {mix }}$ samples. Taking a high wavenumber region into consideration, the samples with nicotinamide show the most prominent differences (Figure 15c,d). 
In the case of the fingerprint region, two different methods of measuring the distance (Euclidean and Chebyshev) were used. The results presented in Figure 15e are grouped into four clusters. The $\mathrm{XN}-\mathrm{NIC}$ and $\mathrm{XN}-\mathrm{NIC}_{\text {mix }}$ samples show the smallest similarities as compared to the other samples (cocrystals and physical mixtures with the same coformer) which are consistent with the above mentioned observations in the region $3700-2700 \mathrm{~cm}^{-1}$. On the other hand, the tree diagram created using the Chebyshev distance in Figure $15 \mathrm{f}$ reveals that the XN sample forms an individual cluster whereas the physical mixtures and suitable cocrystals are merged. This is similar to that calculated by PCA analysis (Figure 14b). Basically, HCA can be used directly with the PCA calculations to simplify the method of discrimination between the cocrystals and physical mixtures.

\section{Materials and Method}

\subsection{Materials}

Xanthohumol purchased from Sigma-Aldrich (Darmstadt, Germany) with purity of $>98 \%$ was recrystallized from acetonitrile. Nicotinamide, glutarimide, acetamide, caffeine, and all used solvents were of analytical grade and were purchased from Sigma-Aldrich. The compounds used as coformers are included in the list of compounds authorized for the safe use as additives to food products, pharmaceutical preparations, and dietary supplements (so-called GRAS list ("Generally Recognized as Safe") created by the FDA-American Food and Drug Agency).

Synthesis of the cocrystals. Xanthohumol and coformers at the 1:1 molar ratio were dissolved in acetonitrile at $30^{\circ} \mathrm{C}$. The concentrated solution was kept for 2 days at room temperature to obtain yellow crystals (with a plate and prismatic shapes) using the slow evaporation solution growth technique. Then crystals were collected from the crystallization vessels.

\subsection{Methods}

\subsubsection{Single Crystal X-ray Diffraction}

Single crystal diffraction data were collected on a Rigaku Oxford Diffraction diffractometer equipped with a MicroMax-007 HF, $\mathrm{Cu}$ rotated anode as an X-ray source $(\mathrm{CuK} \alpha)$, multilayer optic, and a Pilatus $300 \mathrm{~K}$ area detector at $\mathrm{T}=293 \mathrm{~K}$. The $2 \theta$ was measured in a range of $6-110^{\circ}$ with a resolution of $0.078^{\circ}$ and 10 min counting time per frame. Data reduction and cell refinement were carried out using CRYSALIS ${ }^{\mathrm{PRO}}$ [51]. All structures were solved applying direct methods [52] and refined using the Olex2 program [53]. The refinement was based on the squared structure factors $\left(\mathrm{F}^{2}\right)$ for all reflections except those with very negative $\mathrm{F}^{2}$ values. Almost all hydrogen atoms were located in the idealized averaged geometrical positions. The scattering factors were taken from Tables 6.1.1.4 and 4.2.4.2 in [54]. Table 1 includes the experimental details for single crystals measurements. The presented structures were deposited in the Cambridge Crystallographic Data Centre (CCDC) with the numbers: XN-AC 1,955,279, XN-GA 1,955,276, XN-NIC 1,955,269, and XN-CF 1,955,267.

\subsubsection{X-ray Powder Diffraction (PXRD)}

The PXRD patterns of all cocrystals were obtained using the same diffractometer as for the single crystal analysis (Rigaku, Tokyo, Japan) but working in a powder diffraction mode. The samples were mounted in the borosilicate glass capillary tubes (wall thickness of $0.01 \mathrm{~mm}$ and diameter of $1 \mathrm{~mm}$ ). The measured range was from $6.4-50^{\circ}$. For averaging, the sample was rotated around the phi axis. The data were collected using the CRYSALIS ${ }^{\mathrm{PRO}}$ software [51]. New identified phases were selected for further studies. Some results are presented in Figure S12.

\subsubsection{Hirshfeld Surface Analysis}

The Hirshfeld surface analysis and fingerprint plots were generated by the CrystalExplorer 17.5 program. The plots were used to describe various intermolecular interactions especially H-bonds 
which are the most important in the stabilization of crystal net and other contacts present in the structure of $\mathrm{XN}-\mathrm{NIC}, \mathrm{XN}-\mathrm{CF}, \mathrm{XN}-\mathrm{AC}$, and $\mathrm{XN}-\mathrm{GA}$ cocrystals. The crystallographic information file (CIF) was used as input for the analysis. Directions and strengths of intermolecular interactions within the crystals were mapped onto the Hirshfeld surfaces according to the description reported by Abidi et al. [55]. The results of the Hirshfeld surface analysis were presented in Figures S1-S3.

\subsubsection{Solubility Experiment}

Solubility of pure $\mathrm{XN}$ and its cocrystals was determined according to the method employed by Sowa et al. [36] with minor modifications of the amounts of ingredients. Shortly, $1 \mathrm{mg}$ of powder $\mathrm{XN}$ and cocrystals were suspended in $5 \mathrm{~mL}$ of 50:50 $(v / v)$ ethanol-water mixture and stirred in a thermostated vessel at $27^{\circ} \mathrm{C}$. An aliquot of the samples was transferred from the slurry at the intervals of 5, 10, 15, 20, $25,30,35,45,50,55,60$, and $90 \mathrm{~min}$, then filtered with a $0.45 \mu \mathrm{m}$ nylon filter. The electronic absorption spectra were recorded with a double-beam UV-Vis spectrophotometer Cary 300 Bio (Varian) equipped with a Cary Peltier temperature control. The samples were measured in closed quartz cuvettes (Helma) with a pathlength of $1.0 \mathrm{~cm}$ in the wavelength range of $200-600 \mathrm{~nm}$. The absorption coefficient of XN was determined $\left(\varepsilon=24,319 \mathrm{dm}^{3} / \mathrm{mol} \cdot \mathrm{cm}\right)$ from the slope of the absorbance measured at $373 \mathrm{~nm} \mathrm{vs}$. the $\mathrm{XN}$ concentration in a $50 \%$ aqueous $\mathrm{EtOH}$ mixture.

\subsubsection{FTIR Spectroscopy}

The Fourier-transformed infrared absorption spectra were recorded with a 670-IR Varian spectrometer. Typically, 16 scans were collected at the resolution of $4 \mathrm{~cm}^{-1}$. Spectra were obtained in the region between 4000 and $600 \mathrm{~cm}^{-1}$. The laser power was set to $50 \%(0.25 \mathrm{~mW})$. The measurement was made in pellets of $\mathrm{KBr}$ previously dried (1 day) at the temperature of $120^{\circ} \mathrm{C}$. The FTIR spectra were obtained for all starting materials ( $\mathrm{XN}$, coformers), the physical mixture of them (for comparison), and cocrystals. The spectral analysis was processed with the use of the Grams/AI 8.0 software (Thermo Scientific, Waltham, MA, USA).

\subsubsection{Raman Spectroscopy}

All Raman spectra were recorded with a Raman microscope inVia Reflex System from Renishaw (Renishaw Plc., Wotton-Under-Edge, UK), equipped with a charge-coupled device (CCD) detector with a resolution of $1 \mathrm{~cm}^{-1}$. Spectra were collected in triplicate using a 50/0.75 $\times$ NA objective, with accumulation of $1 \mathrm{scan}$ and $10 \mathrm{~s}$ exposure time. The excitation was provided by the $514 \mathrm{~nm}$ line of an argon ion laser with the power set as $1 \%$ or $10 \%$ from $5 \mathrm{~mW}$ (in this case the best spectra were selected). In every case the laser beam was focused on a surface of single crystal placed on an aluminum support. The spectra analysis and correction of a background signal originating from the fluorescence were performed using the Grams/AI 8.0 software (Thermo Scientific, Waltham, MA, USA). All Raman spectra were normalized to the intensity of the most intense band in the range $1750-600 \mathrm{~cm}^{-1}$.

\subsubsection{Multivariate Analysis Principal Component Analysis (PCA)}

\section{Principal Component Analysis (PCA)}

The Principal component analysis is one of the exploratory methods used to detect data structure by searching the explanation of the correlation structure of a set of variables using a smaller set of linear combinations of these variables. The aim of PCA is data reduction with creation of a new set of uncorrelated variables called principal components (PCs) which will explain the largest possible variances [56,57]. The general PCA model can be expressed:

$$
\mathrm{X}=\mathrm{TP}^{\mathrm{T}}
$$


where the $\mathrm{X}$ matrix is decomposed of the dataset into two smaller matrices $\mathrm{T}$ and $\mathrm{P}$ (the scores matrix and loadings matrix, respectively). The loadings illustrate the weight or importance of each variable within the original data and represent the variance for each variable (in this case the wavenumber). Loadings of the PCs are a significant tool for interpretation of the source of the variability inside a dataset from the spectra.

\section{Hierarchical Clustering Analysis (HCA)}

Another chemometrics method that can be a continuation of PCA classification is the hierarchical clustering analysis. HCA is an unsupervised method in which the focus is on the classification problem. The aim of the HCA is to detect similarities in the variables set and classification into clusters. Different classification algorithms can be applied in this method.

Principal component analysis (PCA) and hierarchical cluster analysis (HCA) were used to obtain Raman and FTIR spectra for the cocrystals and crystal form of xanthohumol. Before the data analysis, all spectra were subjected to pre-treatment (multi-point baseline correction, Savitzky-Golay smoothing with 11 points and $\mathrm{Y}$ offset correlation, points were set to zero) using the Grams/AI 8.0 software (Thermo Scientific, Waltham, MA, USA). The analysis was conducted in the range 1700-1000 $\mathrm{cm}^{-1}$ for the Raman spectra and $3700-2700 \mathrm{~cm}^{-1}$ and $1800-1000 \mathrm{~cm}^{-1}$ for the FTIR spectra. In the principal component analysis the covariance matrices were used. In the hierarchical cluster analysis the Euclidean, Chebyshev, and Pearson correlation distance between the pairs of samples were used as a distance measure. Complete and average linkage criteria were used as an agglomeration method. The multivariate analysis was prepared using the Statistica 13 software (TIBCO Software Inc. Palo Alto, CA, USA).

\section{Conclusions}

In summary, for the first time the synthesis of new xanthohumol cocrystals with pharmaceutically acceptable coformers, such as nicotinamide, glutarimide, acetamide, and caffeine in the 1:1 stoichiometry obtained by the slow evaporation solution growth technique was reported. The chemical characteristics of the cocrystals are confirmed by single crystal X-ray diffraction, FTIR, and Raman techniques. The analysis of packing and interactions in the crystal lattice revealed that molecules in the target cocrystals were packed into almost flat layers, formed by the $\mathrm{O}-\mathrm{H} \cdots \mathrm{O}, \mathrm{O}-\mathrm{H} \cdots \mathrm{N}$, and N-H $\cdots \mathrm{O}-\mathrm{type}$ contacts between the xanthohumol and coformer molecules. The single crystal X-ray diffraction study indicated the existence of characteristic hydrogen bond motif in the structures of XN-NIC, $\mathrm{XN}-\mathrm{GA}$, and $\mathrm{XN}-\mathrm{AC}$ cocrystals resulting from the involvement of the hydroxyl group (O4H4) and carbonyl oxygen $(\mathrm{O} 2)$ from the neighboring $\mathrm{XN}$ molecule in layers stabilization. Except for $\mathrm{XN}-\mathrm{CF}$, the hydrogen bonds from the hydroxyl group (A ring) were the main interlayer binding synthons. In the $\mathrm{XN}$ cocrystals with caffeine, the neighboring layers were weakly bonded by both the hydrogen bonds and the $\pi-\pi$ stacking which could account for the low quality of the XN-CF cocrystals. The XN-GA and $\mathrm{XN}-\mathrm{AC}$ cocrystal structures were sustained by the supramolecular hydrogen bonds ring $\mathrm{R}_{6}^{6}(16)$, while the $\mathrm{XN}-\mathrm{NIC}$ cocrystals were bonded by the $\mathrm{C}(6)$ infinite hydrogen chain in the plane of $\mathrm{XN}$ molecules. Furthermore, in all structures under study, the $\pi-\pi$ stacking interactions additionally stabilized layer binding. FTIR spectroscopy confirmed that the crystalline phase of the cocrystals was not only a physical mixture of the initial reactants. A completely different crystal phase reflected the spectral changes, mainly due to the formation of hydrogen bonding between the $\mathrm{XN}$ and coformers molecules. However, the application of Raman spectroscopy gave the insight, to a lesser extent, into the nature of the interactions in the cocrystals.

It was shown that the combination of multivariate statistical methods (PCA and HCA) with the Raman and FTIR spectroscopic data is a screening tool employed for identifying new cocrystal structures and could accelerate this process significantly. Finally, the solubility studies of XN cocrystals revealed a 2.6-fold increase in the $\mathrm{XN}$ solubility for $\mathrm{XN}-\mathrm{AC}$ and, to a lesser extent, for $\mathrm{XN}-\mathrm{GA}$, XN-NIC, and XN-CF (ca. 1.6-, 1.4- and 1.3-fold, respectively) as compared to intact XN. Based on the 
numerous pharmacological activities of $\mathrm{XN}$, the results of the above investigations suggest that the cocrystals can be prospective candidates for future clinical applications. Moreover, determination of the ability to penetrate biological membranes by the new molecular forms of $\mathrm{XN}$ in comparison with pure compounds will be the subject of the next paper.

Supplementary Materials: Crystallographic information files (CIF), PXRD, FTIR, and Raman data (all spectra and band assignments) for individual components and target cocrystals, Hirshfeld surface analysis, and details of the PCA analysis are available as supporting information.

Author Contributions: M.A. and D.M.K. designed the experiments and research plans; I.B. performed most of the experiments (FTIR and Raman spectroscopy), D.M.K. analyzed the X-ray data; M.A. analyzed the spectroscopic data; I.B. performed the multivariate analysis; M.A. and D.M.K. wrote the manuscript with contributions from all authors; M.A. and D.M.K. supervised the project; M.A. provided funding. All authors read and approved the final manuscript.

Acknowledgments: This research was supported in part by PL-Grid Infrastructure and Wroclaw Centre for Networking and Supercomputing. The X-ray diffraction measurements were supported by EcoTech Lublin.

Conflicts of Interest: The authors declare no conflicts of interest.

\section{References}

1. Liu, M.; Hansen, P.E.; Wang, G.Z.; Qiu, L.; Dong, J.J.; Yin, H.; Qian, Z.H.; Yang, M.; Miao, J.L. Pharmacological Profile of Xanthohumol, a Prenylated Flavonoid from Hops (Humulus lupulus). Molecules 2015, 20, 754-779. [CrossRef] [PubMed]

2. Stevens, J.F.; Taylor, A.W.; Clawson, J.E.; Deinzer, M.L. Fate of xanthohumol and related prenylflavonoids from hops to beer. J. Agric. Food Chem. 1999, 47, 2421-2428. [CrossRef] [PubMed]

3. Vandewalle, M. On the synthesis of xanthohumol and isoxanthohumol. Bull. Soc. Chim. Belg. 1961, 70, 163-167. [CrossRef]

4. Verzele, M.; Stockx, J.; Fontijn, F.; Anteunis, A. Xanthohumol, a New Natural Chalkone. Bull. Soc. Chim. Belg. 1957, 66, 452-475. [CrossRef]

5. Jiang, C.H.; Sun, T.L.; Xiang, D.X.; Wei, S.S.; Li, W.Q. Anticancer Activity and Mechanism of Xanthohumol: A Prenylated Flavonoid from Hops (Humulus lupulus L.). Front. Pharmacol. 2018, 9, 530. [CrossRef]

6. Magalhaes, P.J.; Carvalho, D.O.; Cruz, J.M.; Guido, L.F.; Barros, A.A. Fundamentals and Health Benefits of Xanthohumol, a Natural Product Derived from Hops and Beer. Nat. Prod. Commun. 2009, 4, 591-610. [CrossRef]

7. Wei, S.S.; Sun, T.L.; Du, J.; Zhang, B.K.; Xiang, D.X.; Li, W.Q. Xanthohumol, a prenylated flavonoid from Hops, exerts anticancer effects against gastric cancer in vitro. Oncol. Rep. 2018, 40, 3213-3222. [CrossRef]

8. Stevens, J.F.; Page, J.E. Xanthohumol and related prenylflavonoids from hops and beer: To your good health! Phytochemistry 2004, 65, 1317-1330. [CrossRef]

9. Monteiro, R.; Calhau, C.; Silva, A.O.E.; Pinheiro-Silva, S.; Cuerreiro, S.; Gartner, F.; Azevedo, I.; Soares, R. Xanthohumol inhibits inflammatory factor production and angiogenesis in breast cancer xenografts. J. Cell. Biochem. 2008, 104, 1699-1707. [CrossRef]

10. Lee, I.S.; Lim, J.; Gal, J.; Kang, J.C.; Kim, H.J.; Kang, B.Y.; Choi, H.J. Anti-inflammatory activity of xanthohumol involves heme oxygenase-1 induction via NRF2-ARE signaling in microglial BV2 cells. Neurochem. Int. 2011, 58, 153-160. [CrossRef]

11. Albini, A.; Dell'Eva, R.; Vene, R.; Ferrari, N.; Buhler, D.R.; Noonan, D.M.; Fassina, G. Mechanisms of the antiangiogenic activity by the hop flavonoid xanthohumol: NF-kappa B and Akt as targets. FASEB J. 2005, 19,527-529. [CrossRef] [PubMed]

12. Nuti, E.; Bassani, B.; Camodeca, C.; Rosalia, L.; Cantelmo, A.; Gallo, C.; Baci, D.; Bruno, A.; Orlandini, E.; Nencetti, S.; et al. Synthesis and antiangiogenic activity study of new hop chalcone Xanthohumol analogues. Eur. J. Med. Chem. 2017, 138, 890-899. [CrossRef] [PubMed]

13. Li, J.; Zeng, L.; Xie, J.; Yue, Z.Y.; Deng, H.Y.; Ma, X.Y.; Zheng, C.B.; Wu, X.S.; Luo, J.; Liu, M.Y. Inhibition of Osteoclastogenesis and Bone Resorption in vitro and in vivo by a prenylflavonoid xanthohumol from hops. Sci. Rep. 2015. [CrossRef] [PubMed] 
14. Chadwick, L.R.; Nikolic, D.; Burdette, J.E.; Overk, C.R.; Bolton, J.L.; van Breemen, R.B.; Frohlich, R.; Fong, H.H.; Farnsworth, N.R.; Pauli, G.F. Estrogens and congeners from spent hops (Humulus lupulus). J. Nat. Prod. 2004, 67, 2024-2032. [CrossRef] [PubMed]

15. Arczewska, M.; Kamiński, D.M.; Gieroba, B.; Gagoś, M. Acid-Base Properties of Xanthohumol: A Computational and Experimental Investigation. J. Nat. Prod. 2017, 80, 3194-3202. [CrossRef] [PubMed]

16. Kobus-Cisowska, J.; Szymanowska-Powalowska, D.; Szczepaniak, O.; Kmiecik, D.; Przeor, M.; Gramza-Michalowska, A.; Cielecka-Piontek, J.; Smuga-Kogut, M.; Szulc, P. Composition and In Vitro Effects of Cultivars of Humulus lupulus L. Hops on Cholinesterase Activity and Microbial Growth. Nutrients 2019, 11, 1377. [CrossRef] [PubMed]

17. Zhang, B.; Chu, W.; Wei, P.; Liu, Y.; Wei, T. Xanthohumol induces generation of reactive oxygen species and triggers apoptosis through inhibition of mitochondrial electron transfer chain complex I. Free Radic. Biol. Med. 2015, 89, 486-497. [CrossRef]

18. Pang, Y.; Nikolic, D.; Zhu, D.; Chadwick, L.R.; Pauli, G.F.; Farnsworth, N.R.; van Breemen, R.B. Binding of the hop (Humulus lupulus L.) chalcone xanthohumol to cytosolic proteins in Caco-2 intestinal epithelial cells. Mol. Nutr. Food Res. 2007, 51, 872-879. [CrossRef]

19. Van Breemen, R.B.; Yuan, Y.; Banuvar, S.; Shulman, L.P.; Qiu, X.; Alvarenga, R.F.; Chen, S.N.; Dietz, B.M.; Bolton, J.L.; Pauli, G.F.; et al. Pharmacokinetics of prenylated hop phenols in women following oral administration of a standardized extract of hops. Mol. Nutr. Food Res. 2014, 58, 1962-1969. [CrossRef]

20. Amidon, G.L.; Lennernas, H.; Shah, V.P.; Crison, J.R. A theoretical basis for a biopharmaceutic drug classification: The correlation of in vitro drug product dissolution and in vivo bioavailability. Pharm. Res. 1995, 12, 413-420. [CrossRef]

21. Bolla, G.; Nangia, A. Pharmaceutical cocrystals: Walking the talk. Chem. Commun. 2016, 52, 8342-8360. [CrossRef] [PubMed]

22. Schultheiss, N.; Newman, A. Pharmaceutical Cocrystals and Their Physicochemical Properties. Cryst. Growth Des. 2009, 9, 2950-2967. [CrossRef] [PubMed]

23. Chadha, R.; Saini, A.; Arora, P.; Bhandari, S. Pharmaceutical cocrystals: A novel approach for oral bioavailability enhancement of drugs. Crit. Rev. Ther. Drug Carr. Syst. 2012, 29, 183-218. [CrossRef] [PubMed]

24. Karimi-Jafari, M.; Padrela, L.; Walker, G.M.; Croker, D.M. Creating Cocrystals: A Review of Pharmaceutical Cocrystal Preparation Routes and Applications. Cryst. Growth Des. 2018, 18, 6370-6387. [CrossRef]

25. Sinha, A.S.; Maguire, A.R.; Lawrence, S.E. Cocrystallization of Nutraceuticals. Cryst. Growth Des. 2015, 15, 984-1009. [CrossRef]

26. Malamatari, M.; Ross, S.A.; Douroumis, D.; Velaga, S.P. Experimental cocrystal screening and solution based scale-up cocrystallization methods. Adv. Drug Deliv. Rev. 2017, 117, 162-177. [CrossRef] [PubMed]

27. Gajda, M.; Nartowski, K.P.; Pluta, J.; Karolewicz, B. Continuous, one-step synthesis of pharmaceutical cocrystals via hot melt extrusion from neat to matrix-assisted processing-State of the art. Int. J. Pharm. 2019, 558, 426-440. [CrossRef]

28. Xu, J.; Huang, Y.T.; Ruan, S.D.; Chi, Z.L.; Qin, K.M.; Cai, B.C.; Cai, T. Cocrystals of isoliquiritigenin with enhanced pharmacokinetic performance. CrystEngComm 2016, 18, 8776-8786. [CrossRef]

29. Zhu, B.Q.; Zhang, Q.; Wang, J.R.; Mei, X.F. Cocrystals of Baicalein with Higher Solubility and Enhanced Bioavailability. Cryst. Growth Des. 2017, 17, 1893-1901. [CrossRef]

30. Ketkar, S.; Pagire, S.K.; Goud, N.R.; Mahadik, K.; Nangia, A.; Paradkar, A. Tracing the Architecture of Caffeic Acid Phenethyl Ester Cocrystals: Studies on Crystal Structure, Solubility, and Bioavailability Implications. Cryst. Growth Des. 2016, 16, 5710-5716. [CrossRef]

31. Lou, B.Y.; Hu, S.L. Different Hydrogen-Bonded Interactions in the Cocrystals of Nicotinamide with Two Aromatic Acids. J. Chem. Crystallogr. 2011, 41, 1663-1668. [CrossRef]

32. Smith, A.J.; Kavuru, P.; Wojtas, L.; Zaworotko, M.J.; Shytle, R.D. Cocrystals of Quercetin with Improved Solubility and Oral Bioavailability. Mol. Pharm. 2011, 8, 1867-1876. [CrossRef] [PubMed]

33. Karagianni, A.; Malamatari, M.; Kachrimanis, K. Pharmaceutical Cocrystals: New Solid Phase Modification Approaches for the Formulation of APIs. Pharmaceutics 2018, 10, 18. [CrossRef] [PubMed]

34. Power, F.B.; Tutin, F.; Rogerson, H. The constituents of hops. J. Chem. Soc. 1913, 103, 1267-1292. [CrossRef] 
35. Weiskirchen, R.; Mahli, A.; Weiskirchen, S.; Hellerbrand, C. The hop constituent xanthohumol exhibits hepatoprotective effects and inhibits the activation of hepatic stellate cells at different levels. Front. Physiol. 2015, 6, 140. [CrossRef]

36. Sowa, M.; Ślepokura, K.; Matczak-Jon, E. Improving solubility of fisetin by cocrystallization. CrystEngComm 2014, 16, 10592-10601. [CrossRef]

37. Rajput, L.; Sanphui, P.; Desiraju, G.R. New solid forms of the Anti-HIV drug etravirine: Salts, cocrystals, and solubility. Cryst. Growth Des. 2013, 13, 3681-3690. [CrossRef]

38. Guzmán, H.R.; Tawa, M.; Zhang, Z.; Ratanabanangkoon, P.; Shaw, P.; Gardner, C.R.; Chen, H.; Moreau, J.P.; Almarsson, O.; Remenar, J.F. Combined use of crystalline salt forms and precipitation inhibitors to improve oral absorption of celecoxib from solid oral formulations. J. Pharm. Sci. 2007, 96, 2686-2702. [CrossRef]

39. Ramkumar, V.; Anandhi, S.; Kannan, P.; Gopalakrishnan, R. Synthesis, single crystal growth, characterization and comparison of two new enone shifted chalcones and their NLO behaviour. CrystEngComm 2013, 15, 2438-2449. [CrossRef]

40. Arczewska, M.; Kamiński, D.M.; Górecka, E.; Pociecha, D.; Rój, E.; Slawińska-Brych, A.; Gagoś, M. The molecular organization of prenylated flavonoid xanthohumol in DPPC multibilayers: X-ray diffraction and FTIR spectroscopic studies. Biochim. Biophys. Acta 2013, 1828, 213-222. [CrossRef]

41. Ramalingam, S.; Periandy, S.; Govindarajan, M.; Mohan, S. FT-IR and FT-Raman vibrational spectra and molecular structure investigation of nicotinamide: A combined experimental and theoretical study. Spectrochim. Acta A Mol. Biomol. Spectrosc. 2010, 75, 1552-1558. [CrossRef] [PubMed]

42. Karunakaran, V.; Balachandran, V. Experimental and computational study on molecular structure, natural bond orbital and natural hybrid orbital analysis of non-linear optical material trans-3-(o-hydroxyphenyl-1-phenyl)-2-propen-1-one. J. Mol. Struct. 2013, 1053, 66-78. [CrossRef]

43. Falk, M.; Gil, M.; Iza, N. Self-association of caffeine in aqueous solution: An FT-IR study. Can. J. Chem. 1990, 68, 1293-1299. [CrossRef]

44. Bienko, D.C.; Michalska, D.; Roszak, S.; Wojciechowski, W.; Nowak, M.J.; Lapinski, L. Infrared matrix isolation and theoretical studies on glutarimide. J. Phys. Chem. A 1997, 101, 7834-7841. [CrossRef]

45. Brittain, H.G. Vibrational Spectroscopic Studies of Cocrystals and Salts. 1. The Benzamide-Benzoic Acid System. Cryst. Growth Des. 2009, 9, 2492-2499. [CrossRef]

46. Sajan, D.; Binoy, J.; Joe, I.H.; Jayakumar, V.S.; Zaleski, J. Vibrational spectral studies of methyl 3-(4-methoxyphenyl) prop-2-enoate, a new organic non-linearoptic crystal. J. Raman Spectrosc. 2005, 36, 221-236. [CrossRef]

47. Saganowska, P.; Wesolowski, M. Principal component and cluster analyses as supporting tools for co-crystals detection. J. Therm. Anal. Calorim. 2017, 130, 45-55. [CrossRef]

48. Caliandro, R.; Di Profio, G.; Nicolotti, O. Multivariate analysis of quaternary carbamazepine-saccharin mixtures by X-ray diffraction and infrared spectroscopy. J. Pharm. Biomed. Anal. 2013, 78-79, 269-279. [CrossRef]

49. Ong, Y.H.; Lim, M.; Liu, Q. Comparison of principal component analysis and biochemical component analysis in Raman spectroscopy for the discrimination of apoptosis and necrosis in K562 leukemia cells. Opt. Express 2012, 20, 25041-25043. [CrossRef]

50. Bonnier, F.; Byrne, H.J. Understanding the molecular information contained in principal component analysis of vibrational spectra of biological systems. Analyst 2012, 137, 322-332. [CrossRef]

51. CrysAlis PRO; Agilent Technologies Ltd.: Yarnton, Oxfordshire, UK, 2014.

52. Sheldrick, G.M. Phase annealing in SHELX-90: Direct methods for larger structures. Acta Crystallogr. A 1990, A46, 473-478. [CrossRef]

53. Dolomanov, O.V.; Bourhis, L.J.; Gildea, R.J.; Howard, J.A.K.; Puschmann, H. OLEX2: A complete structure solution, refinement and analysis program. J. Appl. Crystallogr. 2009, 42, 339-341. [CrossRef]

54. Berman, H.M.; Westbrook, J.; Feng, Z.; Gilliland, G.; Bhat, T.N.; Weissig, H.; Shindyalov, I.N.; Bourne, P.E. The Protein Data Bank. Nucleic Acids Res. 2000, 28, 235-242. [CrossRef] [PubMed]

55. Abidi, S.S.A.; Azim, Y.; Gupta, A.K.; Pradeep, C.P. Cocrystals of indole-3-acetic acid and indole-3-butyric acid: Synthesis, structural characterization and Hirshfeld surface analysis. J. Mol. Struct. 2018, 1166, $202-213$. [CrossRef]

56. Garbacz, P.; Wesołowski, M. DSC, FTIR and Raman Spectroscopy Coupled with Multivariate Analysis in a Study of Co-Crystals of Pharmaceutical Interest. Molecules 2018, 23, 2136. [CrossRef] [PubMed] 
57. Rodrigues, M.; Lopes, J.; Sarraguca, M. Vibrational Spectroscopy for Cocrystals Screening. A Comparative Study. Molecules 2018, 23, 3263. [CrossRef] [PubMed]

Sample Availability: Samples of the compounds are not available from the authors. 